\title{
Neurochemical Coding of Enteric Neurons in Adult and Embryonic Zebrafish (Danio rerio)
}

\author{
Leen Uyttebroek ${ }^{1}$, lain T. Shepherd ${ }^{2}$, Fernand Harrisson ${ }^{1}$, Guy Hubens ${ }^{3}$, Ronny Blust ${ }^{4}$, \\ Jean-Pierre Timmermans ${ }^{5}$, and Luc Van Nassauw ${ }^{3,5},{ }^{*}$ \\ ${ }^{1}$ Laboratory of Human Anatomy and Embryology, Department of Biomedical Sciences, University \\ of Antwerp, 2020 Antwerpen, Belgium \\ 2Department of Biology, Emory University, Atlanta, Georgia 30322 \\ ${ }^{3}$ Laboratory of Anatomy and Embryology, Faculty of Medicine, University of Antwerp, 2020 \\ Antwerpen, Belgium \\ ${ }^{4}$ Laboratory of Ecophysiology, Biochemistry and Toxicology, Departement of Biology, University \\ of Antwerp, 2020 Antwerpen, Belgium \\ ${ }^{5}$ Laboratory of Cell Biology and Histology, Department of Veterinary Sciences, University of \\ Antwerp, 2020 Antwerpen, Belgium
}

\section{Abstract}

Although the morphology and development of the zebrafish enteric nervous system have been extensively studied, the precise neurochemical coding of enteric neurons and their proportional enteric distribution are currently not known. By using immunohistochemistry, we determined the proportional expression and coexpression of neurochemical markers in the embryonic and adult zebrafish intestine. Tyrosine hydroxylase (TH), vasoactive intestinal peptide (VIP), and pituitary adenylate cyclase-activating peptide (PACAP) were observed only in nerve fibers, whereas other markers were also detected in neuronal cell bodies. Calretinin and calbindin had similar distributions. In embryos, all markers, except for choline acetyltransferase (ChAT) and TH, were present from 72 hours postfertilization. Nitrergic neurons, evenly distributed and remaining constant in time, constituted the major neuronal subpopulation. The neuronal proportions of the other markers increased during development and were characterized by regional differences. In the adult, all markers examined were expressed in the enteric nervous system. A large percentage of enteric neurons displayed calbindin and calretinin, and serotonin was the only marker showing significant distribution differences in the three intestinal regions. Colocalization studies showed that serotonin was not coexpressed with any of the other markers. At least five neuronal subpopulations were determined: a serotonergic, a nitrergic noncholinergic, two cholinergic nonnitrergic subpopulations along with one subpopulation expressing both ChAT and neuronal nitric oxide synthase. Analysis of nerve fibers revealed that nitrergic neurons coexpress VIP and 
PACAP, and that nitrergic neurons innervate the tunica muscularis, whereas serotonergic and cholinergic nonnitrergic neurons innervate the lamina propria and the tunica muscularis.

\section{INDEXING TERMS}

zebrafish; enteric neurons; neurochemical coding

The zebrafish, Danio rerio, is a teleost fish belonging to the family of Cyprinidae along with goldfish and carp. Zebrafish are small $( \pm 3-4 \mathrm{~cm})$ tropical freshwater fish native to the Southern region of Asia and popular in aquariums (Spence et al., 2008). Over the past 15 years, the zebrafish has emerged as a leading model organism in biomedical research because of its genetic and experimental strengths (for review see Grunwald and Eisen, 2002).

The intestine of the zebrafish closely resembles the mammalian intestine. It is a large, convoluted tube that can be subdivided into three regions. Zebrafish, just like other cyprinids, lack a stomach; instead, the proximal intestine (PI), also known as the intestinal bulb, is believed to have an analogous function. The middle intestine (MI) is thought to absorb nutrients and plays a role in mucosal immunity, and the distal part of the intestine (DI) is analogous to the colon (Ng et al., 2005). Although the wall of the gastrointestinal tract in zebrafish shows a high degree of similarity to that of mammals, the zebrafish intestine displays some differences. The zebrafish intestine lacks the muscularis mucosa and tela submucosa present in higher vertebrates and contains epithelial folds rather than villi. Furthermore, the organization of the zebrafish enteric nervous system (ENS) is less complex compared with mammals. No ganglia are observed; instead, single enteric neurons form a myenteric plexus between the longitudinal and the circular smooth muscle layer (for sreview see Wallace et al., 2005; Olsson, 2009).

The development of the zebrafish ENS has been studied extensively (for review see Wallace et al., 2005; Olden et al., 2008; Olsson et al., 2008) and is regulated by conserved molecular programs (for review see Burzynski et al., 2009). In zebrafish, the enteric neuron progenitors are derived from the vagal neural crest. At 30 hours post-fertilization (hpf), the first precursor cells enter the anterior part of the gut primordium (Bisgrove et al., 1997; Shepherd et al., 2004). They migrate caudally as two chains of cells on either side of the gut, proliferating while they migrate and reaching the end of the intestine at about $60 \mathrm{hpf}$ (Shepherd et al., 2004; Elworthy et al., 2005). After this migratory phase, the precursor cells continue to proliferate and differentiate. By $96 \mathrm{hpf}$, enteric neurons have circumferentially colonized the entire gut wall (Shepherd et al., 2004). A significant increase in the number of enteric neurons occurs between 93 and 98 hpf, during which $\pm 40 \%$ of the total number of enteric neurons in the zebrafish are formed (Olden et al., 2008). Regular spontaneous propagating contractions are observed in the zebrafish larvae before the onset of feeding, and these contractions have been shown to be under neuronal control (Holmberg et al., 2004, 2006). Therefore, it can be assumed that the enteric innervation is well developed at the onset of feeding, which occurs at about day 5 postfertilization (dpf; Olsson et al., 2008). 
The ENS is the major system controlling gastrointestinal functions. To understand how it operates, it is necessary to identify the different functional classes of enteric neurons. One way to characterise these different classes is by determining the combinations of neurochemicals (neurotransmitters, neuropeptides, enzymes, calcium-binding proteins $(\mathrm{CaBP})$, carrier proteins, neuroendocrine markers) expressed by the enteric neurons. The neurochemical coding of enteric neurons has already been extensively studied in several mammalian species. The most detailed knowledge about the diverse sets of functional enteric neuron classes has been determined in the guinea pig ileum, for which 14 major neuron classes have been identified (for review see Timmermans et al., 1997; Furness, 2000, 2006; Brookes, 2001). Previous studies investigating the development of the intrinsic enteric innervation of the gut in zebrafish have reported the expression of a number of neurochemicals in the somata and/or fibers of enteric neurons, including the tachykinins, substance $\mathrm{P}$ and neurokinin $\mathrm{A}$, vasoactive intestinal peptide (VIP), pituitary adenylate cyclase-activating peptide (PACAP), serotonin (5-hydroxytryptamine; 5HT), calretinin (CR), calbindin (CB), neuronal nitric oxide synthase (nNOS), and calcitonin gene-related peptide (Poon et al., 2003; Holmberg et al., 2004, 2006; Holmqvist et al., 2004; Levanti et al., 2008; Nazir et al., 2008; Olden et al., 2008; Olsson et al., 2008). Enteric nitrergic neurons can be detected at 2 dpf (Holmqvist et al., 2004; Holmberg et al., 2006), whereas other markers appear later during embryogenesis (Olden et al., 2008; Olsson et al., 2008). However, specific data on the proportions of enteric neurons expressing a specific neurochemical marker and neurochemical codings linked to specific enteric neuron types have not been reported. Furthermore, there is some ambiguity with regard to the proportion of serotonergic neurons in the developing zebrafish ENS. Olsson and coworkers (2008) reported that 5HT-expressing neurons make up $\sim 25 \%$ of the total enteric neuron population at $5 \mathrm{dpf}$, but a quantitative study performed by Olden et al. (2008) indicated that only $\sim 12 \%$ of the enteric neurons express $5 \mathrm{HT}$ at $5 \mathrm{dpf}$.

The aim of our study was to determine the proportional distribution of enteric neurons expressing specific neurochemical markers during the development of the zebrafish ENS, specifically, in embryos at $72 \mathrm{hpf}$ (when the first enteric neuron progenitors begin to differentiate), $96 \mathrm{hpf}$ (when the entire gut wall has been colonized with neuron progenitors), and $120 \mathrm{hpf}$ (at the onset of feeding), and in adult animals. In addition, coexpression patterns of neurochemical markers were determined in order to identify different neuron subtypes in the zebrafish ENS.

\section{MATERIALS AND METHODS}

\section{Fish stock}

Adult zebrafish (Danio rerio) of a domestic aquarium strain, AB wild-type, were purchased from a local supplier and kept at the Laboratory of Human Anatomy and Embryology, University of Antwerp. Zebrafish maintenance and breeding were performed as previously described (Matthews et al., 2002; Westerfield, 2007). Briefly, the animals were kept in colonies in aerated fresh water at $26-28.5^{\circ} \mathrm{C}$ on a $14 / 10$-hour light/dark cycle. The water was continuously filtered both chemically and biologically. Fish were fed daily with commercial aquarium fish food. The animals were allowed to breed spontaneously in 
breeding containers placed in the aquariums. Eggs were collected in the morning shortly after spawning and fertilization ( $0 \mathrm{dpf})$ and transferred to small containers containing embryo medium ( $0.99 \mathrm{mM} \mathrm{MgSO}{ }_{4} \cdot 7 \mathrm{H}_{2} \mathrm{O}, 0.15 \mathrm{mM} \mathrm{KH}_{2} \mathrm{PO}_{4}, 0.04 \mathrm{mM} \mathrm{Na}_{2} \mathrm{HPO}_{4} \cdot 2 \mathrm{H}_{2} \mathrm{O}$, $0.99 \mathrm{mM} \mathrm{CaCl}_{2} \cdot 2 \mathrm{H}_{2} \mathrm{O}, 0.50 \mathrm{mM} \mathrm{KCl}, \mathrm{NaCl}, 7.14 \mathrm{mM} \mathrm{NaHCO}_{3}$ in $\mathrm{dH}_{2} \mathrm{O}$ ) at $28.5^{\circ} \mathrm{C}$ containing $0.003 \%$ 1-phenyl-2-thiourea (Sigma-Aldrich, St. Louis, MO) to inhibit melanin pigment formation. The embryos were staged by hpf and by morphological criteria (Kimmel et al., 1995). At $5 \mathrm{dpf}$, feeding of the embryos was started. All experimental procedures were approved by the ethical committee of the University of Antwerp.

\section{Tissue preparation}

Embryos were collected at 72, 96, or $120 \mathrm{hpf}$ and killed with 0.04\% MS222 (ethyl-maminobenzoate methane-sulphonate; Western Chemical Inc., Ferndale, WA) in embryo medium. Next, the embryos were fixed in $4 \%$ paraformaldehyde (PFA) in $10 \mathrm{mM}$ phosphate-buffered saline (PBS; $\mathrm{pH} 7.4$ ) for 1-4 hours at room temperature. After immersion in PBS containing 0.5\% Triton X-100 for 10 minutes, the embryos were stored at $4^{\circ} \mathrm{C}$ in PBS containing $0.01 \%$ sodium azide until further use.

Adult zebrafish (6-8 months old) were killed in $0.04 \%$ MS222 and decapitated, and the entire intestine was dissected out. The brain tissue of a few animals was also removed and further processed for immunoblotting. The intestine was opened along the mesenteric border and pinned out in a Sylgard-lined Petri dish filled with 4\% PFA in PBS for 2 hours at room temperature. After fixation, whole mounts were thoroughly washed in PBS and further processed for optimal immunocytochemical staining according to a modified procedure of Llewellyn-Smith et al. (1985). Briefly, after rinsing in PBS, the whole mounts were incubated for 1 hour in PBS containing 0.05\% thimerosal. Next, after washing in PBS, they were immersed for 30 minutes in PBS containing $0.1 \% \mathrm{NaBH}_{3} \mathrm{CN}$. Finally, they were rinsed in PBS and stored at $4^{\circ} \mathrm{C}$ in PBS containing $0.01 \%$ sodium azide. The intestine and brain tissue of some animals were isolated and further processed for cryosectioning. First, these tissues were immersed in $4 \%$ PFA for 16 hours at $4^{\circ} \mathrm{C}$. They were then rinsed in PBS, transferred to PBS containing $25 \%$ sucrose, and stored at $4^{\circ} \mathrm{C}$ overnight. Next, they were embedded in Tissue-Tek O.C.T. Compound (Sakura Finetek, Zoeterwoude, The Netherlands), sectioned in a cryostat at $10 \mu \mathrm{m}$, and thaw mounted on SuperFrost Plus glass slides (Microm International GmbH, Walldorf, Germany).

\section{Immunohistochemistry}

Double immunostainings of embryos, adult intestine whole mounts, and cryosections were carried out at room temperature. The samples were rinsed in PBS between each incubation step unless indicated otherwise. The primary and secondary antibodies used in this study as well as their dilutions are listed in Table 1. The antigens in the double-labeling experiments, with primary antisera raised in different species, were simultaneously detected by means of indirect immunofluorescence. By using two primary antisera raised in the same species, a sequential immunostaining technique was performed according to the method of Negoescu et al. (1994). In this procedure, a fluorochrome-conjugated polyclonal monovalent Fab fragment was used to visualize the first primary antibody. These Fab fragments prevent the secondary antibodies, used to detect the second primary antibody, from binding to the first 
primary antibody. The monovalence of the Fab fragments also eliminates the possibility of linking the primary antibody from the second part of the sequential immunostaining procedure. After detection of the first antigen, the samples were washed prior to incubation for 2-4 hours with unlabeled Fab fragments, diluted in PBS, directed against the first primary antibody to block residual binding sites on the first primary antibodies (Lewis Carl et al., 1993). Next, they were rinsed in PBS, and the second antigen was detected and visualized with a standard fluorophore-labeled secondary antibody.

Embryos were processed as previously described (Raible and Kruse, 2000). They were rinsed three times with double-distilled water for 1 hour and transferred for 1 hour to a blocking solution to reduce nonspecific staining. The blocking solution was PBS containing $0.5 \%$ Triton X-100 (Sigma-Aldrich), $0.2 \%$ bovine serum albumin (BSA; Jackson Immunoresearch, West Grove, PA), $1 \%$ dimethyl-sulphoxide, $0.02 \%$ sodium azide, and 5\% normal horse serum (NHS; Jackson Immunoresearch). Next, the embryos were incubated for 16-18 hours in primary antibodies diluted in the blocking solution. After a $3 \times 30$ minutes washing step with PBS containing $0.1 \%$ Triton X-100, the embryos were immersed for 1618 hours in the appropriate secondary antibodies diluted in the blocking solution.

Subsequently, the embryos were rinsed with PBS containing $0.1 \%$ Triton X-100 and stored at $4{ }^{\circ} \mathrm{C}$ in PBS containing $50 \%$ glycerol and $0.02 \%$ sodium azide. To improve visualization of the labeled antigens and to perform quantitative analyzes, the intestines were dissected out and mounted in a glycerol-PBS solution, CitiFluor AF1 (CitiFluor Ltd., London, United Kingdom).

The whole mounts of the adult intestines were rinsed in PBS and pretreated for 30 minutes with PBS containing $50 \mathrm{mM}$ glycine to block free aldehyde groups. To reduce nonspecific immunostaining and to increase tissue permeability, the whole mounts were consecutively transferred for 1 hour to PBS containing 5\% NHS, 0.5\% BSA, and 5\% Triton X-100, prior to incubation for 16-18 hours in primary antibodies diluted in PBS containing $1 \%$ NHS, $0.1 \%$ BSA, and $1 \%$ Triton X-100. After rinsing with PBS, the tissues were incubated for 2 hours in the appropriate secondary antibodies diluted in PBS. Next, the whole mounts were thoroughly rinsed with PBS and mounted in CitiFluor AF1 after carefully scraping off the mucosa.

Cryosections were dried at $37^{\circ} \mathrm{C}$ and consecutively rinsed in PBS. Next, they were pretreated with PBS containing $0.01 \%$ sodium azide, $10 \%$ NHS, $0.1 \%$ BSA, $0.05 \%$ thimerosal, and $0.5 \%$ Triton $\mathrm{X}-100$, before incubation for 18 hours in primary antibodies diluted in PBS containing $0.01 \%$ sodium azide, $10 \%$ NHS, $0.1 \%$ BSA, and $0.05 \%$ thimerosal. After being rinsed with PBS, the sections were incubated for 2 hours in the appropriate secondary antibodies diluted in PBS. Finally, the cryosections were washed with PBS and mounted in CitiFluor AF1.

To improve immunostaining with primary antibodies raised in goat, BSA in blocking and dilution solutions was replaced by acetylated BSA (BSA-c; Aurion, Wageningen, The Netherlands). The specificity of secondary antibodies was tested by omitting the primary antisera separately and together in each protocol used. No aspecific staining was observed. Interference control stainings were performed as described by Negoescu et al. (1994). These 
stainings showed no linking of the second-step secondary antibody with the first-step primary antibody or of the second-step primary antibody with the first-step secondary antibody. Cryosections of brain tissue were used as positive controls.

\section{Primary antibodies}

All primary antibodies were chosen on the basis of previous morphological studies performed in zebrafish. We used two pan-neuronal markers, an antibody directed against human neuron-specific $\mathrm{HuC} / \mathrm{HuD}$ proteins $(\mathrm{Hu})$ and an antibody directed against acetylated a-tubulin (a-tub). Hu proteins belong to the embryonic lethal abnormal visual system family of RNA-binding proteins and are involved in many posttranscriptional mechanisms for the development and maintenance of the nervous system. Three members, i.e., HuB, $\mathrm{HuC}$, and $\mathrm{HuD}$, are neuron-specific proteins that are present in the cytoplasm and nucleus of neurons (Fornaro et al., 2007). The anti-Hu antibody has been previously shown to label specifically neuronal cell bodies in zebrafish (Olsson et al., 2008; Olsson, 2009) and is considered the most appropriate antibody in mammals with which to obtain reliable estimates of total numbers of enteric neurons (Lin et al., 2002). The anti-a-tub antibody specifically detects neuronal fibers and, to some extent, neuronal cell bodies in zebrafish (Wallace et al., 2005; Olsson, 2009). Staining of brain cryosections produced a pattern of immunoreactivity (IR) that was identical to previous descriptions for a-tub (Pellegrini et al., 2007) and $\mathrm{Hu}$ (Zupanc et al., 2005) proteins.

The characterization, specificity, and reliability of the antibodies directed against PACAP, nNOS, and choline acetyltransferase (ChAT) and their application in morphological studies of the zebrafish ENS have already been described in detail by Olsson et al. (2008). Preabsorption of these primary antisera according the guidelines of the suppliers led to complete elimination of the immunostaining in all cases. Immunostaining of brain cryosections showed a distribution of IR similar to that previously detected for PACAP (Mathieu et al., 2004), ChAT (Clemente et al., 2004), and nNOS (Holmqvist et al., 2000) in zebrafish brain.

The specificity of the anti-5HT antibody is assumed to be similar in all vertebrate species, because the neurotransmitter 5HT is identical in all vertebrate species (Olsson et al., 2008). Moreover, this antibody has already been used to detect serotonergic neurons in the ENS of mutant and wild-type zebrafish embryos (Pietsch et al., 2006). We preincubated the anti-5HT antibody with $20 \mu \mathrm{g} / \mathrm{ml}$ 5HT/BSA conjugate (Immunostar, Hudson, WI), which completely blocked immunostaining. Furthermore, IR observed in cryosections of zebrafish brain with this anti-5HT antibody was similar to previous stainings in the zebrafish brain (Kaslin and Panula, 2001).

The monoclonal antibody directed against $\mathrm{TH}$ recognizes an epitope on the outside of the regulatory N-terminus of $\mathrm{TH}$ purified from PC12 cells that shows $70 \%$ homology with the zebrafish TH. This antibody has been used to detect catecholaminergic neurons in the central and peripheral nervous system of the zebrafish (Chen et al., 2009). Moreover, the band labelled by this antibody in immunoblots of the zebrafish brain is similar in size ( 62 $\mathrm{kD})$ to that in immunoblots of the rainbow trout (Linard et al., 1998). Staining of brain 
cryosections gave a pattern of IR similar to previous observations (Kaslin and Panula, 2001). The immunogen was not commercially available to perform a preabsorption experiment.

According to the supplier, the anti-VIP antibody directed against synthetic VIP coupled to bovine thyroglobulin with a carbodiimide linker detects VIP in the zebrafish. The antibody has been used to reveal peptidergic neurons in the wall of the zebrafish swim bladder (Finney et al., 2006). VIP, just like PACAP, is highly conserved in vertebrates (Olsson and Holmgren, 2001). Furthermore, the distribution of VIP IR in cryosections of brain was similar to that observed in a previous study in zebrafish (Mathieu et al., 2001). It was also shown that preabsorption of the antiserum with $20 \mu \mathrm{g} / \mathrm{ml}$ synthetic VIP (Sigma-Aldrich) eliminated IR, whereas preabsorption with $20 \mu \mathrm{g} / \mathrm{ml}$ bovine thyroglobulin (AbD Serotec, Oxford, United Kingdom) had no effect on the immunostaining.

The anti-CR antibody is directed against recombinant rat CR showing $71 \%$ homology with zebrafish CR. This antibody has previously been used to label amacrine cells in the zebrafish retina (Yeo et al., 2009). The anti-CB antibody has also been used in previous studies in zebrafish and other fish species to label neurons in the central nervous system (CNS; Zupanc et al., 2005; Ikenaga et al., 2006; Gran̂a et al., 2008) and the ENS (Olsson, 2008), although at present only a predicted protein sequence is available for zebrafish (XP 001341604; http:// www.ncbi.nlm.nih.gov). The immunostaining of both CaBPs in brain tissue was similar to that in previous studies performed in zebrafish (Zupanc et al., 2005; Castro et al., 2006). All CB IR was abolished when the primary antibody was preabsorbed with $5 \mu \mathrm{g} / \mathrm{ml}$ recombinant rat CB (SWant, Belinzona, Switzerland). No effect on the immunostaining was observed when the $\mathrm{CR}$ antibody was preincubated with recombinant rat $\mathrm{CB}$. Furthermore, the specificity of both antibodies was tested by immunoblotting. Homogenates of zebrafish brains were made according to Levanti et al. (2008). Briefly, the brain tissue was immersed for 30 minutes in an ice-cold lysis buffer, T-PER Tissue Protein Extraction Reagent (Thermo Fisher Scientific Inc., Waltham, MA) containing Halt Protease Inhibitor Single Use Cocktail (Thermo Fisher Scientific Inc.) and 3\% ethylenediaminetetraacetic acid, prior to homogenization using mechanical grinding and small ceramic beads in the homogenator Precellys 24 (Bertin Technologies, Montigny, France). Homogenates were centrifuged at $14,000 \mathrm{rpm}$ during 60 minutes at $4^{\circ} \mathrm{C}$, and the supernatants were stored at $-20^{\circ} \mathrm{C}$ until further use. Next, the supernatants were thawed, diluted in the Lane Marker Reducing Sample Buffer (Thermo Fisher Scientific Inc.) and heated for 5 minutes at $95^{\circ} \mathrm{C}$. Samples were then analyzed by SDS-polyacrylamide gel electrophoresis on gradient gels (8-16\% Precise Protein Gels; Thermo Fisher Scientific Inc.) and transferred to a nitrocellulose membrane (Hybond ECL; GE Healthcare, Munich, Germany). These membranes were immersed in a blocking buffer, Super-Block T20 (Thermo Fisher Scientific Inc.), and consecutively incubated overnight at room temperature with a primary antibody diluted in SuperBlock T20. After washing in PBS containing $0.05 \%$ Tween20, they were incubated for 2 hours at room temperature with a horseradish peroxidase (HRP)-conjugated secondary antibody (Table 1) diluted in PBS. Binding was visualized by using the SuperSignal West Pico kit (Thermo Fisher Scientific Inc.). Images were taken with the gel documentation system G:Box (Syngene Europe, Cambridge, United Kingdom) and analyzed with GeneTools analysis software (Syngene Europe). In immunoblots of zebrafish brain, bands of appropriate size (i.e., $\sim 28 \mathrm{kD}$ for $\mathrm{CR}$ and $\sim 26 \mathrm{kD}$ for $\mathrm{CB}$ ) were observed (Fig. 1). 


\section{Analysis and imaging}

The immunostained embryos and whole mounts were evaluated by using a Zeiss AxioPhot epifluorescence microscope (Carl Zeiss Microimaging GmbH, Göttingen, Germany) equipped with an Olympus DP70 digital camera system (Olympus Belgium NV, Aartselaar, Belgium) and the laser scanning microscope LSM510 Meta equipped with an argon-ion and helium-neon laser system (Carl Zeiss Microimaging $\mathrm{GmbH}$ ). The images shown in this paper are composites or projection views from a series of optical sections made with the LSM510 Meta. Contrast and brightness were adjusted in LSM Image Browser Release 4.2 (Carl Zeiss Microimaging GmbH), and montages were made in Adobe Photoshop 7.0 (Adobe Systems Inc., San Jose, CA).

For the quantitative analysis, immunoreactive nerve cell bodies in the myenteric plexus were counted and sized per visual frame $\left(8.2 \times 10^{4} \mu \mathrm{m}^{2}\right)$ in whole-mount preparations or embryonic intestines in the software Cell ${ }^{\wedge} \mathrm{P}$ (Olympus Soft Imaging Solutions, Münster, Germany). Ten randomly chosen frames in each of the three regions of the adult intestine were analyzed. In embryonic intestines, the three regions were delineated using morphological features previously described by $\mathrm{Ng}$ and coworkers (2005), and each region was completely analyzed. The number of immunoreactive neurons was calculated, and the proportional expression of a neurochemical marker in enteric neurons was estimated based on the number of $\mathrm{Hu}$-expressing neurons. In addition, the proportional coexpression of neurochemical markers was determined in the adult intestine. For each experiment, eight embryonic intestines for each developmental stage $(n=8)$ and three adult intestines $(n=3)$ were analyzed. The results are expressed as means $\pm \mathrm{SD}$, and were analyzed by ANOVA followed by a Student-Newman-Keuls test when appropriate. Significance was assumed at $P$ $<0.05$.

\section{RESULTS}

\section{Zebrafish embryos}

Simultaneous detection of $\mathrm{Hu}$ and a-tub revealed that the number and density of enteric neurons increased in the embryonic intestine from $72 \mathrm{hpf}$ to $120 \mathrm{hpf}$. At each embryonic stage, enteric neurons were present in each region of the intestine, with approximately 50\% located in the MI. Examination of the distribution of the neurochemical markers in the zebrafish ENS at the three embryonic stages revealed only nNOS, 5HT, CR, and CB IR in neuronal cell bodies. Quantitative data on the proportional distribution of these four neurochemical markers in enteric neurons during embryonic development are depicted in Figures 2 and 3. The mean size of the enteric neurons' soma (72 hpf: $24 \pm 8 \mu \mathrm{m}^{2} ; 96$ hpf: 24 $\pm 8 \mu \mathrm{m}^{2} ; 120$ hpf: $22 \pm 8 \mu^{2}$ ) did not significantly change between the different points in time measured, between neurons with a different neurochemical content, or between the intestinal regions.

The neurochemical marker expressed predominantly in the enteric neurons was nNOS (Fig. $4 \mathrm{a}-\mathrm{c})$. More than $40 \%$ of the enteric neurons expressed nNOS IR at $72 \mathrm{hpf}$, and this proportion remained constant during further embryonic development. The PI contained a 
significant lower proportion of nitrergic neurons than the two other intestinal regions (pooled values PI $36 \% \pm 7 \%$; MI $44 \% \pm 9 \%$; DI $48 \% \pm 11 \%$ ).

The other three markers, 5HT, CB, and CR, were also expressed in enteric neurons at 72 hpf, and their proportion significantly increased in the later stages. 5HT IR was present mainly in neuronal cell bodies. The highest number of 5HT-immunoreactive neurons was found in the MI, and the highest proportion of 5HT-expressing neurons was detected in the PI. The percentage of 5HT-positive neurons significantly decreased from the PI to the DI (72 hpf: PI $20 \% \pm 10 \%$; MI 10\% $\pm 3 \%$; DI 6\% $\pm 6 \%$; 96 hpf: PI $27 \% \pm 7 \%$; MI $20 \% \pm 5 \%$; DI $14 \% \pm 3 \%$; 120 hpf: PI $31 \% \pm 15 \%$; MI $28 \% \pm 9 \%$; DI $23 \% \pm 8 \%$ ) at each embryonic stage examined. We also observed, in the intestinal wall, 5HT-positive Hu-negative cells, which are 5HT-producing enteroendocrine cells as previously described (Olsson et al., 2008; Fig. 4d-f).

The proportional expression of both $\mathrm{CaBP}$ in the intestinal segments was similar at each of the embryonic stages examined. The highest proportion of CR-expressing neurons was observed in the MI at each embryonic stage (72 hpf: 10\% $\pm 3 \%$; 96 hpf: $20 \% \pm 5 \%$; $120 \mathrm{hpf}$ : $24 \% \pm 8 \%$; Fig. $4 \mathrm{~g}-\mathrm{i})$. At $72 \mathrm{hpf}$, the PI and DI contained a very low percentage of CRpositive neurons (values: PI: $4 \% \pm 5 \%$; DI: $3 \% \pm 4 \%$ ). In some fish, CR-positive neurons were even absent in the PI and DI. At 96 hpf, a significant increase was observed in the PI $(13 \% \pm 5 \%)$, whereas CR-expressing neurons in the DI $(2 \% \pm 3 \%)$ were still rare or completely absent. Although the proportion of CR-expressing neurons in the entire intestine had increased by $120 \mathrm{hpf}$, a significantly lower percentage of these neurons was observed in the DI compared with the other intestinal regions (PI: $20 \% \pm 8 \%$; MI: $24 \% \pm 8 \%$; DI: $10 \% \pm$ $9 \%)$. The expression pattern of CB in the ENS was similar to that of CR; i.e., the highest percentage of CB-positive neurons was found in the MI (72 hpf: 8\% $\pm 5 \%$; $96 \mathrm{hpf}: 20 \% \pm$ $6 \% ; 120 \mathrm{hpf}: 27 \% \pm 5 \%$ ), and a significantly lower proportion was seen in the DI (72 hpf: $3 \% \pm 4 \%$; 96 hpf: $3 \% \pm 3 \% ; 120$ hpf: $12 \% \pm 5 \%$; Fig. 5a-c).

At 72 hpf, VIP and PACAP IR were also detected in the ENS. However, no immunostaining was observed in neuronal cell bodies for either marker; instead, IR was present in varicositylike structures along nerve fibers (Fig. 5d-i). VIP- or PACAP-expressing cell bodies were detected in the intestine, but these cells did not express Hu IR and were not located in the same focal plane as the Hu-positive neurons. These cells were likely to be enteroendocrine cells (Olsson et al., 2008). Although ChAT IR was observed in the CNS at each of the embryonic stages examined, no ChAT-expressing neuronal cell bodies or fibers were observed in the intestine. Furthermore, no TH IR was detected in any of the three embryonic stages in the CNS and ENS.

\section{Adult zebrafish}

Simultaneous detection of $\mathrm{Hu}$ and $\mathrm{a}$-tub in the intestine of adult zebrafish revealed that the density of enteric neurons significantly increased from the PI to the DI (Figs. 6, 7a). Moreover, just as in the embryonic intestine, VIP and PACAP IR were not detected in neuronal cell bodies, whereas IR was present in varicosity-like structures along enteric nerve fibers and in some epithelial enteroendocrine cells (Fig. 7b,c). Furthermore, in the myenteric plexus, TH IR was observed in nerve fibers. In the PI, Hu-positive TH-expressing cells were 
found at the serosal side of the intestinal wall (Fig. 7d). Immunostaining of the other neurochemical markers, ChAT, CB, CR, 5HT, and nNOS, was found in nerve fibers and in neuronal cell bodies (Fig. 7e-i). The quantitative data on the proportional distribution of these markers in the adult zebrafish ENS are presented in Table 2 and depicted in Figure 8. The mean size of the neuronal cell bodies in the adult intestine $\left(85 \pm 30 \mu \mathrm{m}^{2}\right)$ did not significantly change between neurons expressing ChAT, CB, CR, or nNOS. The average size of the 5HT-positive neurons' somas $\left(101 \pm 21 \mu \mathrm{m}^{2}\right)$ was significantly greater than the mean size of the neuronal cell bodies expressing other neurochemical markers. Moreover, in the DI, the average size of the 5HT-positive somata $\left(76 \pm 17 \mu \mathrm{m}^{2}\right)$ was significantly lower than in the PI $\left(112 \pm 32 \mu \mathrm{m}^{2}\right)$ or the MI $\left(114 \pm 29 \mu \mathrm{m}^{2}\right)$. No significant changes between the three intestinal regions were observed for the mean sizes of neuronal cell bodies expressing ChAT, CB, CR, or nNOS.

5HT IR was observed not only in neuronal cell bodies and nerve fibers but also in some epithelial cells (Fig. 7e). It was also clearly demonstrated, based on the orientation of the axon hillocks and of the axons, that the majority of the 5HT-positive neurons $(52 \% \pm 12 \%)$ sent their axons in the oral direction, whereas $13 \% \pm 2 \%$ project mainly aborally. As also observed in the embryonic intestine, the proportion of serotonergic neurons significantly decreased from the proximal part $(25 \% \pm 8 \%)$ to the distal part $(11 \% \pm 3 \%)$ of the intestine.

In contrast to the embryonic intestine, cholinergic neurons were visualized in the adult intestine. ChAT IR was found in neuronal cell bodies and nerve fibers (Fig. 7f), and ChATpositive neurons were equally distributed in the three intestinal regions (mean percentage of cholinergic enteric neurons $39 \% \pm 6 \%$ ).

The adult intestine revealed a similar expression pattern for both CB $(43 \% \pm 6 \%)$ and CR $(45 \% \pm 7 \%)$ compared with the ENS in the embryonic zebrafish (Fig. $7 \mathrm{~g}, \mathrm{~h})$. No significant variation was observed in their proportional distribution among the three intestinal regions. In the MI and DI, some CB- and CR-expressing epithelial cells were also found.

The percentage of nitrergic neurons decreased to $23 \% \pm 3 \%$ compared with the embryonic intestine (Fig. 7i). In contrast to the embryonic intestine, nitrergic neurons were equally distributed in each region of the adult zebrafish intestine.

Double immunolabelings were performed to reveal the coexpression of neurochemical markers in the enteric neurons. The quantitative results of these stainings are presented in Table 3 and immunostainings are depicted in Figures 9 and 10. No regional differences were found for any of the coexpressions. The most striking results were that $\mathrm{CB}$ and $\mathrm{CR}$ were present in the same neurons (Fig. 9a-c; i.e., colocalization of CB and CR was 100\%) and that 5HT was not coexpressed with any of the other neurochemical markers (Fig. 9d-i). Furthermore, $84 \% \pm 11 \%$ of the CB-positive neurons and $85 \% \pm 11 \%$ of the CR-positive neurons displayed ChAT IR and, conversely, $93 \% \pm 1 \%$ of the cholinergic neurons appeared to express CB IR, whereas $96 \% \pm 5 \%$ expressed CR IR (Fig. 10a-c). In addition, 37\% \pm $15 \%$ of the CB-expressing and and $39 \% \pm 15 \%$ of the CR-expressing neurons showed immunostaining for nNOS (Fig. 10d-f). A small number of the cholinergic neurons (7\% \pm $4 \%$ ) expressed nNOS IR, whereas $11 \% \pm 1 \%$ of the nitrergic neurons displayed ChAT IR 
(Fig. 10g-i). Based on these data, five enteric neuronal subpopulations were identified: neurons expressing 1) $\mathrm{CB}, \mathrm{CR}, \mathrm{ChAT}$, and $\mathrm{nNOS}$ ( $\pm 3 \%$ of all enteric neurons); 2$) \mathrm{CB}, \mathrm{CR}$, and nNOS ( $\pm 15 \%$ of all enteric neurons); 3 ) CB, CR, and ChAT ( $\pm 35 \%$ of all enteric neurons); 4 ) only ChAT ( $\pm 5 \%$ of all enteric neurons); or 5 ) only $5 \mathrm{HT}$ ( $\pm 18 \%$ of all enteric neurons).

Furthermore, double immunostainings revealed that VIP and PACAP completely colocalized in enteric nerve fibers (Fig. 11a-c). In addition, almost all nNOSimmunoreactivie nerve fibers coexpressed VIP and PACAP IR (Fig. 11d-f). This result indicated that the previously described nitrergic neuronal subpopulations also coexpress VIP and PACAP. However, not all VIP- and PACAP-immunoreactive nerve fibers coexpressed nNOS IR.

Finally, immunostainings of cryosections clearly showed that, in each intestinal segment, nerve fibers expressing nNOS IR were found predominantly in the tunica muscularis (Fig. $11 \mathrm{~g}$ ). In the lamina propria, nitrergic nerve fibers were observed adjacent to blood vessels. Serotonergic nerve fibers were detected in the tunica muscularis but also were abundant in the lamina propria (Fig. 11h). Nerve fibers expressing VIP (Fig. 11i), PACAP, CB, or CR (Fig. 11j) were observed in the lamina propria and in the tunica muscularis. However, in the lamina propria of the PI, the CaBP-expressing fibers were less numerous, as in the other intestinal regions. These results demonstrate that, in the zebrafish intestine, nitrergic neurons innervate predominantly the enteric smooth muscle, whereas serotonergic and cholinergic nonnitrergic neurons innervate the enteric smooth muscle, the lamina propria, and the epithelium.

\section{DISCUSSION}

The present study sought define the proportional distribution of enteric neurons expressing specific neurochemical markers in the zebrafish during early development and in the adult. In the embryonic intestine, all the markers that we investigated were expressed from $72 \mathrm{hpf}$, except for ChAT and TH. Only nNOS, 5HT, CB, and CR were detected in neuronal cell bodies, permitting the proportional distribution of these markers to be determined, but VIP and PACAP were only found in nerve fibers. A high percentage of nitrergic neurons was observed, and their numbers remained constant throughout embryonic development. By contrast, lower proportions were detected for the other three markers, which increased at later stages and were also characterized by regional differences. In the adult intestine, all neurochemical markers were expressed, but only ChAT, CB, CR, nNOS, and 5HT were present in neuronal cell bodies and on nerve fibers, whereas VIP, PACAP, and TH were only observed on nerve fibers. A major proportion of enteric neurons in the adult intestine displayed CaBP IR, but 5HT was the only marker to show a significant distribution difference in the three intestinal regions. Colocalization studies showed that both $\mathrm{CB}$ and $\mathrm{CR}$ were expressed in the same neurons and that 5HT was not coexpressed with any of the other markers. At least five neuronal sub-populations were characterized: $\mathrm{CB}^{+} / \mathrm{CR}^{+} / \mathrm{ChAT}^{+} /$ $\mathrm{nNOS}^{+}, \mathrm{CB}^{+} / \mathrm{CR}^{+} / \mathrm{nNOS}^{+} / \mathrm{ChAT}^{-}{ }_{-}, \mathrm{CB}^{+} / \mathrm{CR}^{+} / \mathrm{ChAT}^{+} / \mathrm{nNOS}^{-}{ }_{-}, \mathrm{ChAT}^{+} / \mathrm{CB}^{-} / \mathrm{CR}^{-} /$ $\mathrm{nNOS}^{-}$, and $5 \mathrm{HT}^{+}$-expressing neurons. Analysis of immunostaining of nerve fibers revealed that nitrergic neurons also coexpressed VIP and PACAP. Moreover, nitrergic 
neurons innervate predominantly the enteric smooth muscle, whereas serotonergic and cholinergic nonnitrergic neurons innervate the enteric smooth muscle, the lamina propria, and the epithelium.

Although we detected VIP and PACAP in enteric nerve fibers of the embryonic and adult intestine, no IR was observed in neuronal cell bodies. Similar observations have been reported in mammals. To overcome this lack of VIP and PACAP IR in the mammalian gastrointestinal tract, gastrointestinal whole mounts, prior to fixation, are incubated in vitro in a colchicine-containing culture medium to increase IR in nerve cell bodies (Furness et al., 1984). Colchicine is known to cause derangement of cellular microtubules, which leads to inhibition of axonal transport and accumulation of axonally transported substances in the neuronal cell body (CeccatelLi et al., 1991; Boyer et al., 1994). We attempted to use this approach in zebrafish, but it did not yield immunostaining of neuronal cell bodies. However, previous zebrafish studies suggest that VIP and PACAP coexist in enteric neurons, as observed in other nonmammalian species (Olsson and Holmgren, 1994, 2001; Olsson et al., 2008). The present study clearly demonstrated that VIP and PACAP are coexpressed in the ENS of the adult zebrafish. Some of the VIP- and PACAP-expressing nerve fibers were assumed to be intrinsic to the intestine (Olsson et al., 2008). In addition, zebrafish vagal nerve may also account for some of the VIP- and PACAP-positive nerve fibers in the intestine. For other teleost species, vagal neurons expressing VIP and PACAP have been reported (Olsson and Holmgren, 1994). Although we observed VIP- and PACAPimmunoreactive enteric nerve fibers in zebrafish embryos at $72 \mathrm{hpf}$, PACAP-containing enteric nerve fibers appear already to be present at $48 \mathrm{hpf}$ in the PI and MI (Holmberg et al., 2004). By using digital motion analysis, an inhibitory effect of PACAP on the wave frequency of anterogradely propagating waves has been previously demonstrated at $5 \mathrm{dpf}$ (Holmberg et al., 2004). These data indicate that the VIP/PACAP inhibitory pathway is already developed before the onset of feeding. Previous studies in sea bass also suggest that VIP may play a role in the physiological maturation of the intestinal epithelium during embryonic development (Pederzoli et al., 2004).

In agreement with the study of Olsson and colleagues (2008), we did not find any ChAT IR in the embryonic intestine, although pharmacological studies in zebrafish embryos clearly indicated that acetylcholine release may modulate gut motility from 4 dpf onward (Holmberg et al., 2004, 2007). The proportional size of the cholinergic neuronal population in the adult zebrafish intestine $( \pm 39 \%)$ did not correlate with data obtained from mammals. For mouse ileum, it was found that $60-70 \%$ of the myenteric neurons are cholinergic (Sang and Young, 1998; Qu et al., 2008), whereas, in the human gastrointestinal tract, cholinergic neurons account for 50-70\% of all intrinsic neurons (Anlauf et al., 2003).

In agreement with previous studies, we did not observe TH IR in the embryonic intestine (Guo et al., 1999; Olsson et al., 2008). However, as in these other studies, we observed the presence of TH-immunoreactive nerve fibers in the myenteric plexus and of TH-IR vagal neurons at the serosal side of the adult intestine. It is assumed that the TH-positive nerve fibers are of extrinsic origin, arising from TH-expressing vagal neurons. However, it cannot be excluded that some of these nerve fibers are intrinsic to the intestine. TH-expressing neurons have been described in the submucous and myenteric plexus in several mammalian 
species (Schemann et al., 1995; Sann et al., 1998; Anlauf et al., 2003; Chiocchetti et al., 2004; Li et al., 2004, 2006; Chevalier et al., 2008; Qu et al., 2008; Tian et al., 2008; Mongardi Fantaguzzi et al., 2009). They appear late during perinatal development of the ENS, and their precise function remains unclear.

Zebrafish enteric neurons expressing nNOS IR appear first in the DI and MI between 40 and 55 hpf and, 1 day later, also in the PI of the embryonic zebrafish intestine (Holmqvist et al., 2004; Holmberg et al., 2006). In agreement with these previous studies, we found that nitrergic neurons constitute a major neuronal subpopulation in the embryonic intestine. The percentage of nitrergic neurons remains constant during the developmental time points we examined (72-120 hpf), and the proximal part of the intestine contained a significant lower proportion of nitrergic neurons than the other two regions of the intestine. Despite the presence of enteric nitrergic neurons at this early stage, an NO-mediated inhibitory tonus has been reported to be present only just before or at the onset of exogenous feeding (Holmberg et al., 2006). This is similar to what has been suggested for other vertebrate species (Timmermans et al., 1994; Van Ginneken et al., 1998, 2001; Bagyanszki et al., 2000; Belai and Burnstock, 2000; Bayram et al., 2002; Pederzoli et al., 2007). Furthermore, an additional role for nNOS has been proposed in the development and differentiation of the embryonic zebrafish gut (Holmqvist et al., 2004). In the adult zebrafish intestine, the percentage of nitrergic neurons $( \pm 23 \%)$ was comparable to the proportional values obtained in the myenteric plexus of the mouse ( $\pm 29 \%$; Qu et al., 2008) and rat ( $\pm 27 \%$; Belai et al., 1995) ileum.

The main source of 5HT in the body is the gut, where it is expressed in enterochromaffin cells and in intrinsic neurons. 5HT acts as an enteric neurotransmitter and as a mucosal signalling molecule. It is involved in initiating motility and secretory reflexes. For the embryonic zebrafish, we observed that 5HT-expressing enteric neurons were already present in the intestine at $72 \mathrm{hpf}$, before the onset of oral feeding, as has been previously reported by Olden et al. (2008). The percentage of 5HT-positive neurons significantly decreased from the PI to the DI. The proportional value obtained at $120 \mathrm{hpf}$ was comparable to the value estimated by Olsson et al. (2008). Previous studies in guinea pig revealed that 5HT signaling in the gut is required for the postnatal development of motility patterns before the onset of oral intake of nutrition (Bian et al., 2007). For the adult zebrafish intestine, we observed a similar distribution pattern of 5HT-expressing neurons, although the percentage of 5HTexpressing neurons was lower than that in the embryonic intestine. In contrast to the mammalian gut, 5HT-expressing enteroendocrine cells were sparsely distributed in the zebrafish intestine, which is consistent with previous studies (Olsson et al., 2008). This indicates that the enteric neurons are the main source of 5HT in the zebrafish intestine.

$\mathrm{CB}$ and CR are members of the EF-hand (E-helix-loop-F-helix) family of CaBP, which also includes parvalbumin, calmodulin, and $\mathrm{S} 100$ protein, and are widely distributed in the central and peripheral nervous systems (Christakos et al., 1989). Although their putative role in neurons remains to be elucidated, it is known that they are involved in the regulation of all aspects of cell function (Grabarek, 2006). One report has emphasized a role for CB as a neuroprotective protein (Iacopino et al., 1994). In the mammalian gut, CR and CB are expressed in several neuronal subpopulations. In the myenteric plexus of the mouse and 
guinea pig ileum, $\mathrm{CB}$ has been found exclusively in intrinsic primary afferent or sensory neurons (IPANs; Timmermans et al., 1997; Furness, 2000, 2006; Brookes, 2001; Qu et al., 2008; Mongardi Fantaguzzi et al., 2009). In the sheep ileum, CB is also expressed in other neuron types (Chiocchetti et al., 2004), whereas, in the rabbit ileum, CB is expressed predominantly in cholinergic interneurons (Dénes and Gábriel, 2004). In the pig small intestine, CB is coexpressed with 5HT in interneurons and viscerofugal neurons (Timmermans et al., 1997). The vast majority of IPANs in the human small intestine express CR and a minority CB (Brehmer et al., 2004a). In the rat small intestine, IPANs express CR, but CB is expressed in other neuron types (Sayegh and Ritter, 2003). In mouse, CR is also found in IPANs (Qu et al., 2008). In the guinea pig ileum, CR is expressed in interneurons, secretomotor neurons, and excitatory motor neurons, whereas, in the pig small intestine, CR is found in interneurons and inhibitory motor neurons (Timmermans et al., 1997; Furness, 2000, 2006; Brookes, 2001). Our results show a similar distribution pattern for CB and CR in both the embryonic and the adult zebrafish intestine. Similar neuronal colocalization of CB and CR has been reported for the vagal lobe of the goldfish (Ikenaga et al., 2006). Partial coexpression of $\mathrm{CB}$ and $\mathrm{CR}$ in enteric neurons has been reported for the mouse (Qu et al., 2008) and sheep (Chiocchetti et al., 2004) ileum and for the rat small intestine (Sayegh and Ritter, 2003). The percentages of enteric neurons displaying CR or CB IR in zebrafish do not correlated with the proportional values obtained in mammals for both these $\mathrm{CaBP}$ (Chiocchetti et al., 2004; Qu et al., 2008).

In mammals, coexpression of neurochemical markers has been used to determine different neuronal classes, which are functionally classified as motor neurons (excitatory or inhibitory), sensory neurons, interneurons, secretomotor neurons, vasodilator neurons, and viscerofugal neurons (Timmermans et al., 1997, 2001; Furness, 2000, 2006; Brookes, 2001; Qu et al., 2008). Colocalization studies of the five neurochemicals, CB, CR, ChAT, 5HT, and nNOS, in the adult zebrafish intestine has allowed us to distinguish five neuronal subpopulations covering approximately $75 \%$ of all enteric neurons. One subpopulation contained neurons expressing only $5 \mathrm{HT}$ and was found to project mainly orally.

Serotonergic neurons are commonly present in the fish intestine (Watson, 1979; Goodrich et al., 1980; Anderson, 1983; Jensen and Holmgren, 1985; Anderson and Campbell, 1988; Kiliaan et al., 1989; Karila et al., 1998; Olden et al., 2008; Olsson et al., 2008) and are assumed to play a role in the regulation of intestinal motility and in epithelial function (Jensen and Holmgren, 1985; Kiliaan et al., 1989; Karila et al., 1998). In mammals, serotonergic neurons are designated as descending interneurons (Timmermans et al., 1997, 2001; Furness, 2000, 2006; Brookes, 2001; Qu et al., 2008). For fish, it has been suggested that the orally directed serotonergic neurons are ascending excitatory neurons and the anally projecting ones are descending interneurons (Karila et al., 1998).

Our identification of a small group of intrinsic neurons displaying only ChAT IR requires further investigation in order to ascribe a specific function to this neuronal sub-population. The three remaining subpopulations displayed CB and CR IR. The smallest subpopulation also expressed ChAT and nNOS. In mammals, coexpression of ChAT and nNOS occurred in a small group of descending interneurons (Timmermans et al., 1997, 2001; Furness, 2000, 2006; Porter et al., 2002; Brehmer et al., 2004b; Qu et al., 2008). Nonadrenergic, 
noncholinergic nitrergic neurons in mammals have been characterized as inhibitory motor neurons, which also express VIP (Porter et al., 1997; Timmermans et al., 1997; Furness, 2000; Brookes, 2001; Jungbauer et al., 2006; Qu et al., 2008). For the zebrafish, we have observed that nitrergic nerve fibers are present predominantly in the tunica muscularis and coexpress VIP and PACAP. This being the case, we suggest that the CB/CR/nNOSexpressing neurons in the zebrafish intestine modulate intestinal motility. Coexpression of $\mathrm{CB}$ and CR with ChAT in mammals has been observed in the murine intestine in some intrinsic sensory neurons (Qu et al., 2008), in a small population of irregularly shaped enteric neurons of the sheep ileum (Chiocchetti et al., 2004), and in putative motor neurons of the gastric corpus in the guinea pig (Reiche et al., 2001). Coexpression of both CaBPs in cholinergic neurons has not been observed in other mammals. As a result, further neurochemical characterization is needed to determine the neuron type corresponding to the $\mathrm{CB} / \mathrm{CR} / \mathrm{ChAT}$-coding type in zebrafish.

In conclusion, this is the first study with zebrafish to show the proportional expression of neurochemical markers in the ENS during embryonic development as well as the colocalization of neurochemical markers in enteric neurons of the adult intestine. From early stages in embryonic development, nearly all of the neurochemical markers that we investigated are expressed. During embryonic development, the major proportion of enteric neurons is nitrergic, and the proportional distributions of the neurochemical markers that we examined in this study exhibit regional differences in the developing intestine. Coexpression of neurochemical markers in the adult intestine revealed a serotonergic, a nitrergic, and two cholinergic neuronal subpopulations, and one subpopulation expressing both ChAT and nNOS. Further studies are required on the neuronal function of these different neuronal subpopulations that we have identified in the zebrafish intestine. The information provided here will also serve as a basis for future studies investigating the effects of mutations, toxic substances, drugs, and inflammation on the development and function of the zebrafish ENS.

\section{Acknowledgments}

The authors thank Mrs. E. Goeman, Mrs. M. Van Geel, and Mr. D. De Rijck for their technical assistance.

Grant sponsor: Special Research Fund of the University of Antwerp; Grant number: KP2974 (to L.V.N.); Grant sponsor: National Institutes of Health; Grant number: R01 DK067285 (to I.T.S.).

\section{LITERATURE CITED}

Anderson C. Evidence for 5-HT-containing intrinsic neurons in the teleost intestine. Cell Tissue Res. 1983; 230:377-386. [PubMed: 6406067]

Anderson C, Campbell G. Immunohistochemical study of 5-HT-containing neurons in the teleost intestine: relationship to the presence of enterochromaffin cells. Cell Tissue Res. 1988; 254:553559. [PubMed: 3233650]

Anlauf M, Schäfer MK-H, Eiden L, Weihe E. Chemical coding of the human gastrointestinal nervous system: cholinergic, VIPergic, and catecholaminergic phenotypes. J Comp Neurol. 2003; 459:90111. [PubMed: 12629668]

Bagyanszki M, Roman V, Fekete E. Quantitative distribution of NADPH-diaphorase-positive myenteric neurons in different segments of the developing chicken small intestine and colon. Histochem J. 2000; 32:679-684. [PubMed: 11272808] 
Bayram Z, Asar M, Çayli S, Demir R. Immunocytochemical detection of neuronal nitric oxide synthase (nNOS)-IR in embryonic rat stomach between days 13 and 21 of gestation. J Histochem Cytochem. 2002; 50:671-679. [PubMed: 11967278]

Belai A, Burnstock G. Pattern of distribution and co-localization of NOS and ATP in the myenteric plexus of human fetal stomach and intestine. Neuroreport. 2000; 11:5-8. [PubMed: 10683820]

Belai A, Cooper S, Burnstock G. Effect of age on NADPH-diaphorase-containing myenteric neurones of rat ileum and proximal colon. Cell Tissue Res. 1995; 279:379-383. [PubMed: 7895275]

Bian X, Patel B, Dai X, Galligan JJ, Swain G. High mucosal serotonin availability in neonatal guinea pig ileum is associated with low serotonin transporter expression. Gastroenterology. 2007; 132:2438-2447. [PubMed: 17570217]

Bisgrove BW, Raible DW, Walter V, Eisen JS, Grunwald DJ. Expression of $c$-ret in the zebrafish embryo: potential roles in motoneuronal development. J Neurobiol. 1997; 33:749-768. [PubMed: 9369149]

Boyer PA, Trembleau A, Leviel V, Arluison M. Effects of intranigral injections of colchicine on the expression of some neuropeptides in the rat forebrain: an immunohistochemical and in situ hybridization study. Brain Res Bull. 1994; 33:541-560. [PubMed: 7514485]

Brehmer A, Croner R, Dimmler A, Papadopoulos T, Schrödl F, Neuhuber W. Immunohistochemical characterization of putative primary afferent (sensory) myenteric neurons in human small intestine. Auton Neurosci. 2004a; 112:49-59. [PubMed: 15233930]

Brehmer A, Schrödl F, Neuhuber W, Tooyama I, Kimura H. Co-expression pattern of neuronal nitric oxide synthase and two variants of choline acetyltransferase in myenteric neurons of porcine ileum. J Chem Neuroanat. 2004b; 27:33-41. [PubMed: 15036361]

Brookes SJH. Classes of enteric nerve cells in the guinea-pig small intestine. Anat Rec. 2001; 262:5870. [PubMed: 11146429]

Burzynski G, Shepherd IT, Enomoto H. Genetic model system studies of the development of the enteric nervous system, gut motility and Hirschsprung's disease. Neurogastroenterol Motil. 2009; 21:113-127. [PubMed: 19215589]

Castro A, Becerra M, Manso MJ, Anadón R. Calretinin immunoreactivity in the brain of the zebrafish, Danio rerio: distribution and comparison with some neuropeptides and neurotransmittersynthesizing enzymes. II. Midbrain, hindbrain, and rostral spinal cord. J Comp Neurol. 2006; 494:792-814. [PubMed: 16374815]

Ceccatelli S, Cortés R, Hökfelt T. Effect of reserpine and colchicine on neuropeptide mRNA levels in the rat hypothalamic paraventricular nucleus. Brain Res Mol Brain Res. 1991; 9:57-69. [PubMed: 1850078]

Chen Q, Huang N-N, Huang J-T, Chen S, Fan J, Li C, Xie F-K. Sodium benzoate exposure downregulates the expression of tyrosine hydroxylase and dopamine transporter in dopaminergic neurons in developing zebrafish. Birth Defects Res (B). 2009; 86:85-91.

Chevalier J, Derkinderen P, Gomes P, Thinard R, Naveilhan P, Vanden Berghe P, Neunlist M. Activity-dependent regulation of tyrosine hydroxylase expression in the enteric nervous system. $\mathrm{J}$ Physiol. 2008; 586:1963-1975. [PubMed: 18258664]

Chiocchetti R, Grandis A, Bombardi C, Clavenzani P, Costerbosa GL, Lucchi ML, Furness JB. Characterisation of neurons expressing calbindin immunoreactivity in the ileum of the unweaned and mature sheep. Cell Tissue Res. 2004; 318:289-303. [PubMed: 15338268]

Christakos S, Gabrielides C, Rhoten WB. Vitamin D-dependent calcium binding proteins: chemistry, distribution, functional considerations, and molecular biology. Endocr Rev. 1989; 10:3-26. [PubMed: 2666110]

Clemente D, Porteros A, Weruaga E, Alonso JR, Arenzana FJ, Aijón J, Arévalo R. Cholinergic elements in the zebrafish central nervous system: histochemical and immunohistochemical analysis. J Comp Neurol. 2004; 474:75-107. [PubMed: 15156580]

Dénes V, Gábriel R. Calbindin-immunopositive cells are cholinergic interneurons in the myenteric plexus of rabbit ileum. Cell Tissue Res. 2004; 318:465-472. [PubMed: 15378349]

Elworthy S, Pinto JP, Pittefer A, Cancela ML, Kelsh RN. Phox2b expression in the enteric nervous system is conserved in zebrafish and is sox10-dependent. Mech Dev. 2005; 122:659-669. [PubMed: 15817223] 
Finney JL, Robertson GN, McGee CAS, Smith FM, Croll RP. Structure and autonomic innervation of the swim bladder in the zebrafish (Danio rerio). J Comp Neurol. 2006; 495:587-606. [PubMed: 16498679]

Fornaro M, Raimondo S, Lee JM, Giacobini-Robecchi MG. Neuron-specific Hu proteins sub-cellular localization in primary sensory neurons. Ann Anat. 2007; 189:223-228. [PubMed: 17534028]

Furness JB. Types of neurons in the enteric nervous system. J Auton Nerv Syst. 2000; 81:87-96. [PubMed: 10869706]

Furness, JB. The enteric nervous system. Oxford: Blackwell Publishing; 2006.

Furness JB, Costa M, Keast JR. Choline acetyltransferase- and peptide immunoreactivity of submucous neurons in the small intestine of the guinea-pig. Cell Tissue Res. 1984; 237:329-336. [PubMed: 6206951]

Grabarek Z. Structural basis for diversity of the EF-hand calcium-binding proteins. J Mol Biol. 2006; 359:509-525. [PubMed: 16678204]

Gran̂a P, Anadón R, Yánez J. Immunocytochemical study of calretinin and calbindin D-28K expression in the retina of three cartilaginous fishes and a clastidian (Polypterus). Brain Res Bull. 2008; 75:375-378. [PubMed: 18331901]

Goodrich JT, Bernd P, Sherman D, Gershon MD. Phylogeny of enteric serotonergic neurons. J Comp Neurol. 1980; 190:15-28. [PubMed: 6966633]

Grunwald DJ, Eisen JS. Headwaters of the zebrafish: emergence of a new model vertebrate. Nat Rev Genet. 2002; 3:717-724. [PubMed: 12209146]

Guo S, Wilson SW, Cooke S, Chitnis AB, Driever W, Rosenthal A. Mutations in the zebrafish unmask shared regulatory pathways controlling the development of catecholaminergic neurons. Dev Biol. 1999; 208:473-487. [PubMed: 10191060]

Holmberg A, Schwerte T, Pelster B, Holmgren S. Ontogeny of the gut motility control system in zebrafish Danio rerio embryos and larvae. J Exp Biol. 2004; 207:4085-4094. [PubMed: 15498954]

Holmberg A, Olsson C, Holmgren S. The effects of endogenous and exogenous nitric oxide on gut motility in zebrafish Danio rerio embryos and larvae. J Exp Biol. 2006; 209:2472-2479. [PubMed: 16788030]

Holmberg A, Olsson C, Hennig GW. TTX-sensitive and TTX-insensitive control of spontaneous gut motility in the developing zebrafish (Danio rerio) larvae. J Exp Biol. 2007; 210:1084-1091. [PubMed: 17337720]

Holmqvist B, Ellingsen B, Alm P, Forsell J, Øyan A-M, Goksøyr A, Fjose A, Seo H-C. Identification and distribution of nitric oxide synthase in the brain of adult zebrafish. Neurosci Lett. 2000; 292:119-122. [PubMed: 10998563]

Holmqvist B, Ellingsen B, Forsell J, Zhdanova I, Alm P. The early ontogeny of neuronal nitric oxide synthase systems in the zebrafish. J Exp Biol. 2004; 207:923-935. [PubMed: 14766951]

Iacopino AM, Quintero EM, Miller EK. Calbindin-D28K: a potential neuroprotective protein. Neurodegeneration. 1994; 3:1-20.

Ikenaga T, Huesa G, Finger TE. Co-occurrence of calcium-binding proteins and calcium-permeable glutamate receptors in the primary gustatory nucleus of goldfish. J Comp Neurol. 2006; 499:90 105. [PubMed: 16958099]

Jensen J, Holmgren S. Neurotransmitters in the intestine of the Atlantic cod, Gadus morhua. Comp Biochem Physiol. 1985; 82C:81-89.

Jungbauer C, Lindig TM, Schrödl F, Neuhuber W, Brehmer A. Chemical coding of myenteric neurons with different axonal projection patterns in the porcine ileum. J Anat. 2006; 209:733-743. [PubMed: 17118061]

Karila P, Shahbazi F, Jensen J, Holmgren S. Projections and actions of tachykininergic, cholinergic, and serotonergic neurones in the intestine of the Atlantic cod. Cell Tissue Res. 1998; 291:403413. [PubMed: 9477297]

Kaslin J, Panula P. Comparative anatomy of the histaminergic and other aminergic systems in zebrafish (Danio rerio). J Comp Neurol. 2001; 440:342-377. [PubMed: 11745628]

Kiliaan AJ, Joosten HWJ, Bakker R, Dekker K, Groot JA. Serotonergic neurons in the intestine of two teleosts, Carassius auratus and Oreochromis mossambicus, and the effect of serotonin on 
transepithelial ion-selectivity and muscle tension. Neuroscience. 1989; 31:817-824. [PubMed: 2594202]

Kimmel CB, Ballard WM, Kimmel SR, Ullmann B, Schilling TF. Stages of embryonic development of the zebrafish. Dev Dyn. 1995; 203:253-310. [PubMed: 8589427]

Levanti MB, Montalbano G, Laura R, Ciriaco E, Cobo T, Garcia-Suarez O, Germanà A, Vega JA. Calretinin in the peripheral nervous system of the adult zebrafish. J Anat. 2008; 212:67-71. [PubMed: 18173770]

Lewis Carl SA, Gilette-Ferguson I, Ferguson DG. An indirect immunofluorescence procedure for staining the same cryostat section with two mouse monoclonal primary antibodies. J Histochem Cytochem. 1993; 41:1273-1278. [PubMed: 7687266]

Li ZS, Pham TD, Tamir H, Chen JJ, Gershon MD. Enteric dopaminergic neurons: definition, developmental lineage, and effects of extrinsic denervation. J Neurosci. 2004; 24:1330-1339. [PubMed: 14960604]

Li ZS, Schmauss C, Cuenca A, Ratcliffe E, Gershon MD. Physiological modulation of intestinal motility by enteric dopaminergic neurons and the D2 receptor: analysis of dopamine receptor expression, location, development, and function in wild-type and knock-out mice. J Neurosci. 2006; 26:2798-2807. [PubMed: 16525059]

Lin Z, Gao N, Hu H-Z, Liu S, Gao C, Kim G, Ren J, Xia Y, Peck OC, Wood JD. Immunoreactivity of $\mathrm{Hu}$ proteins facilitates identification of myenteric neurones in guinea-pig small intestine. Neurogastroenterol Motil. 2002; 14:197-204. [PubMed: 11975720]

Linard B, Pakdel F, Marmignon MH, Saligaut C. Cloning of a cDNA coding for active tyrosine hydroxylase in the rainbow trout (Oncorhynchus mykiss): comparison with other hydroxylases and enzymatic expression. J Neurochem. 1998; 71:920-928. [PubMed: 9721717]

Llewelyn-Smith IJ, Costa M, Furness JB. Light and electron microscopic immunocytochemistry of the same nerves from whole mount preparations. J Histochem Cytochem. 1985; 9:857-866.

Mathieu M, Tagliafierro G, Angelini C, Vallarino M. Organization of vasoactive intestinal peptide-like immunoreactive system in the brain, olfactory organ and retina of the zebrafish, Danio rerio, during development. Brain Res. 2001; 888:235-247. [PubMed: 11150480]

Mathieu M, Ciarlo M, Trucco N, Griffero F, Damonte G, Salis A, Vallarino M. Pituitary adenylate cyclase-activating polypeptide in the brain, spinal cord and sensory organs of the zebrafish, Danio rerio, during development. Brain Res Dev Brain Res. 2004; 151:169-185.

Matthews M, Trevarrow B, Matthews J. A virtual tour of the guide for zebrafish users. Lab Anim. 2002; 31:34-40.

Mongardi Fantaguzzi C, Thacker M, Chiocchetti R, Furness JB. Identification of neuron types in the sub-mucosal ganglia of the mouse ileum. Cell Tissue Res. 2009; 336:179-189. [PubMed: 19326148]

Nazir A, Polynice M, Chant-Haphavong R, Elha II, Buchholz BM, Stuckenholz C, Bahary N, Bauer AJ. The adult zebrafish (Danio rerio) as a model of gastrointestinal motility. Neurogastroenterol Motil. 2008; 20(Suppl 1):14.

Negoescu A, Labat-Moleur F, Lorimier P, Lamarcq L, Guillermet C, Chambaz E, Brambilla E. F(ab) secondary antibodies: a general method for double immunolabeling with primary antisera from the same species. Efficiency control by chemiluminescence. J Histochem Cytochem. 1994; 42:443437.

Ng ANY, de Jong-Curtain TA, Mawdsley DJ, White SJ, Shin J, Appel B, Dong PD, Stainier DY, Heatj JK. Formation of the digestive system in zebrafish: III. Intestinal epithelium morphogenesis. Dev Biol. 2005; 286:114-135. [PubMed: 16125164]

Olden T, Akhtar T, Beckman SA, Wallace KN. Differenation of the zebrafish enteric nervous system and intestinal smooth muscle. Genesis. 2008; 46:484-498. [PubMed: 18781646]

Olsson C. Calbindin-immunoreactive nerve cells in the zebrafish gut. Neurogastroenterol Motil. 2008; 20(Suppl 1):44.

Olsson C. Autonomic innervation of the fish gut. Acta Histochem. 2009; 111:185-195. [PubMed: 19124149] 
Olsson C, Holmgren S. Distribution of PACAP (pituitary adenylate cyclase-activating polypeptide)like and helospectin-like peptides in the teleost gut. Cell Tissue Res. 1994; 277:539-547. [PubMed: 7954690]

Olsson C, Holmgren S. The control of gut motility. Comp Biochem Physiol A. 2001; 128:481-503.

Olsson C, Holmberg A, Holmgren S. Development of enteric and vagal innervation of the zebrafish (Danio rerio) gut. J Comp Neurol. 2008; 508:756-770. [PubMed: 18393294]

Pederzoli A, Bertacchi I, Gambarelli A, Mola L. Immunolocalisation of vasoactive intestinal peptide and substance P in the developing gut of Dicentrarchus labrax (L.). Eur J Histochem. 2004; 48:179-184. [PubMed: 15208087]

Pederzoli A, Conte A, Tagliazucchi D, Gambarelli A, Mola L. Occurrence of two NOS isoforms in the developing gut of sea bass Dicentrarchus labrax (L.). Histol Histopathol. 2007; 22:1057-1064. [PubMed: 17616932]

Pellegrini E, Mouriec K, Anglade I, Menuet A, Le Page Y, Gueguen M-M, Marmignon M-H, Brion F, Pakdel F, Kah O. Identification of aromatase-positive radial cells as progenitor cells in the ventricular layer of the forebrain in zebrafish. J Comp Neurol. 2007; 501:150-167. [PubMed: 17206614]

Pietsch J, Delalande J-M, Jakaitis B, Stensby JD, Dohle S, Talbot WS, Raible DW, Shepherd IT. lessen Encodes a zebrafish trap100 required for enteric nervous system development. Development. 2006; 133:395-406. [PubMed: 16396911]

Poon KL, Richardson M, Lam CS, Khoo HE, Korzh V. Expression pattern of neuronal nitric oxide synthase in embryonic zebrafish. Gene Expr Patterns. 2003; 3:463-466. [PubMed: 12915313]

Porter AJ, Wattchow DA, Brookes SJH, Costa M. The neurochemical coding and projections of circular muscle motor neurons in the human colon. Gastroenterology. 1997; 113:1916-1923. [PubMed: 9394731]

Porter AJ, Wattchow DA, Brookes SJH, Costa M. Cholinergic and nitrergic interneurones in the myenteric plexus of the human colon. Gut. 2002; 51:70-75. [PubMed: 12077095]

Qu Z-D, Thacker M, Castelucci P, Bagyanszki M, Epstein ML, Furness JB. Immunohistochemical analysis of neuron types in the mouse small intestine. Cell Tissue Res. 2008; 334:147-161. [PubMed: 18855018]

Raible DW, Kruse GJ. Organization of the lateral line system in embryonic zebrafish. J Comp Neurol. 2000; 421:189-198. [PubMed: 10813781]

Reiche D, Huber K, Hoppe S, Schemann M. Neurochemically distinct myenteric neurone populations containing calbindin have specific distribution patterns around the circumference of the gastric corpus. Cell Tissue Res. 2001; 303:319-328. [PubMed: 11320647]

Sang Q, Young HM. The identification and chemical coding of cholinergic neurons in the small and large intestine of the mouse. Anat Rec. 1998; 251:185-199. [PubMed: 9624448]

Sann H, Hoppe S, Baldwin L, Grundy D, Schemann M. Presence of putative neurotransmitters in the myenteric plexus of the gastrointestinal tract and in the musculature of the urinary bladder of the ferret. Neurogastroenterol Motil. 1998; 10:35-47. [PubMed: 9507249]

Sayegh AI, Ritter RC. Morphology and distribution of nitric oxide synthase-, neurokinin-1 receptor-, calretinin-, cal-bindin-, and neurofilament-M-immunoreactive neurons in the myenteric and submucosal plexuses of the rat small intestine. Anat Rec. 2003; 271A:209-216.

Schemann M, Schaaf C, Mader M. Neurochemical coding of enteric neurons in the guinea pig stomach. J Comp Neurol. 1995; 353:161-178. [PubMed: 7538152]

Shepherd IT, Pietsch J, Elworthy S, Kelsh RN, Raible DW. Roles for GFRa 1 receptors in zebrafish enteric nervous system development. Development. 2004; 131:241-249. [PubMed: 14660438]

Spence R, Gerlach G, Lawrence C, Smith C. The behaviour and ecology of the zebrafish, Danio rerio. Biol Rev Camb Philos Soc. 2008; 83:13-34. [PubMed: 18093234]

Tian Y-M, Chen X, Luo D-Z, Zhang X-H, Xue H, Zheng L-F, Yang N, Wang X-M, Zhu J-X. Alteration of dopaminergic markers in gastrointestinal tract of different rodent models of Parkingson's disease. Neuroscience. 2008; 153:634-644. [PubMed: 18420351]

Timmermans J-P, Barbiers M, Scheuermann DW, Bogers JJ, Adriaensen D, Fekete E, Mayer B, Van Marck EA, De Groodt-Lasseel MHA. Nitric oxide synthase immunoreactivity in the enteric 
nervous system of the developing human digestive tract. Cell Tissue Res. 1994; 275:235-245. [PubMed: 7509262]

Timmermans J-P, Adriaensen D, Cornelissen W, Scheuermann DW. Structural organization and neuropeptide distribution in the mammalian enteric nervous system, with special attention to those components involved in mucosal reflexes. Comp Biochem Physiol. 1997; 118A:331-340.

Timmermans J-P, Hens J, Adriaensen D. Outer submucous plexus: an intrinsic nerve network involved in both secretory and motility processes in the intestine of large mammals and humans. Anat Rec. 2001; 262:71-78. [PubMed: 11146430]

Van Ginneken C, Van Meir F, Sommereyns G, Sys S, Weyns A. Nitric oxide synthase expression in enteric neurons during development in the pig duodenum. Anat Embryol. 1998; 198:399-408. [PubMed: 9801059]

Van Ginneken C, Van Meir F, Sys S, Weyns A. Stereo-logic description of the changing expression of constitutive nitric oxide synthase and heme oxygenase in the enteric plexuses of the pig small intestine during development. J Comp Neurol. 2001; 437:118-128. [PubMed: 11477601]

Wallace KN, Akhter S, Smith EM, Lorent K, Pack M. Intestinal growth and differentiation in zebrafish. Mech Dev. 2005; 122:157-173. [PubMed: 15652704]

Watson AH. Fluorescent histochemistry of the teleost gut: evidence for the presence of serotonergic neurones. Cell Tissue Res. 1979; 197:155-164. [PubMed: 455398]

Westerfield, M. A guide for the laboratory use of zebrafish (Danio rerio). 5. Eugene, OR: University of Oregon Press; 2007. The zebrafish book.

Yeo J-Y, Lee E-S, Jeon C-J. Parvalbumin-immunoreactive neurons in the inner nuclear layer of zebrafish retina. Exp Eye Res. 2009; 88:553-560. [PubMed: 19084520]

Zupanc GKH, Hinsch K, Gage FH. Proliferation, migration, neuronal differentiation, and long-term survival of new cells in the adult zebrafish brain. J Comp Neurol. 2005; 488:290-319. [PubMed: 15952170] 


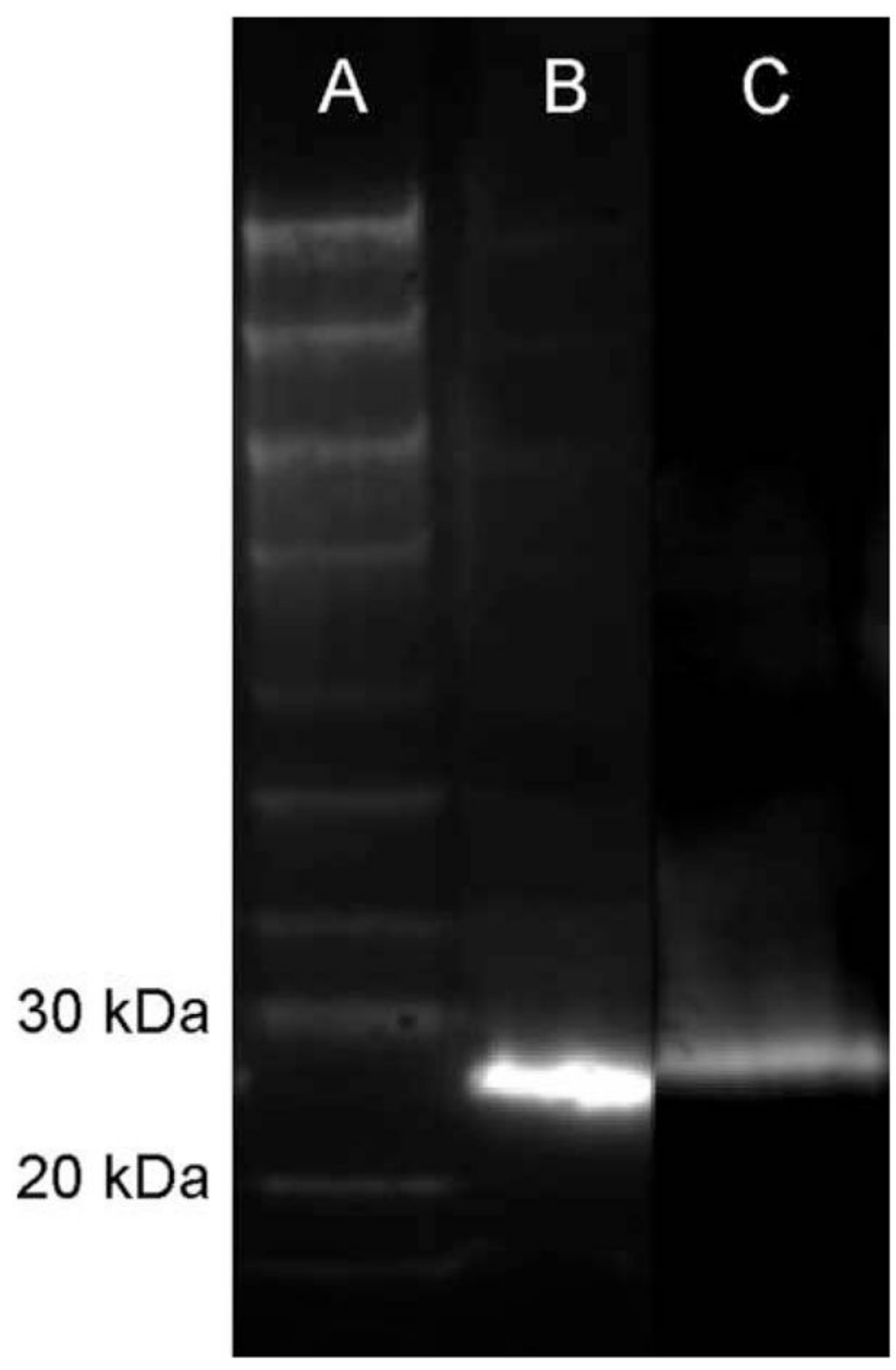

Figure 1.

Western blot analysis of CaBP in zebrafish. Lane A: Bio-tinylated protein ladder; lane B: blot of brain homogenate immunostained with the anti-CR antibody revealing a band of \pm 28 $\mathrm{kD}$; lane $\mathrm{C}$ : blot of brain homogenate immunostained with the anti-CB antibody revealing a band of $\sim 26 \mathrm{kD}$. 


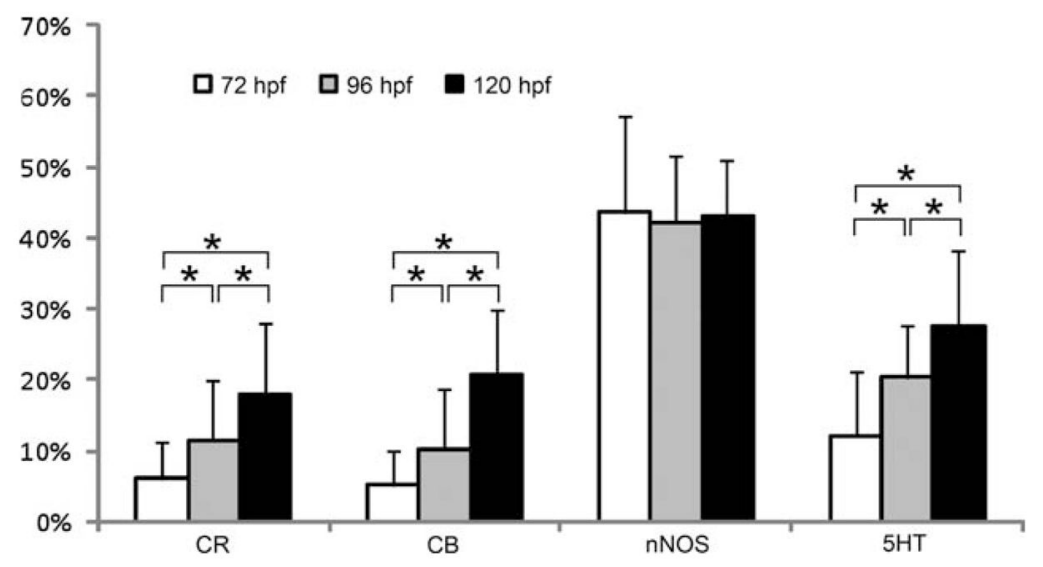

Figure 2.

Average proportional distribution of $\mathrm{CR}, \mathrm{CB}, \mathrm{nNOS}$, and $5 \mathrm{HT}$ in the zebrafish ENS during development between hatching (72 hpf) and onset of oral feeding (120 hpf). $* P<0.05$. 
a

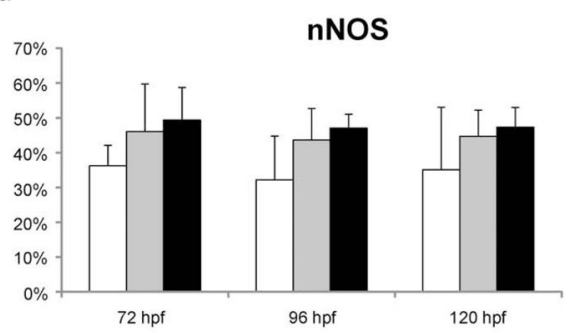

C

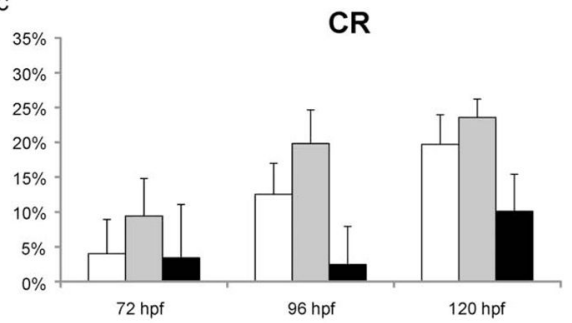

b

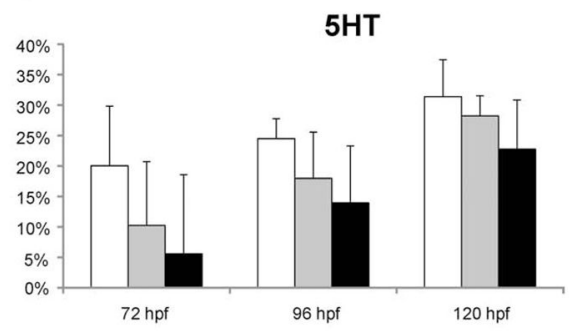

d $\quad$ CB

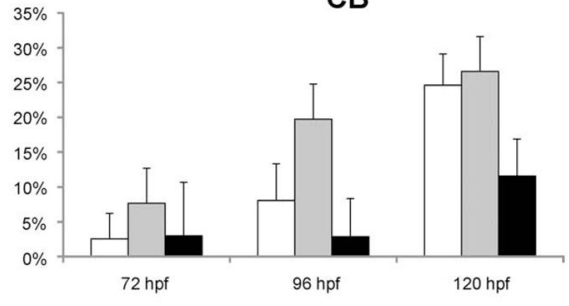

口PI पMI घDI

Figure 3.

Average proportional distribution of enteric neurons expressing nNOS (a), 5HT (b), CR (c), or CB (d) in the proximal (PI), middle (MI), and distal (DI) parts of the zebrafish intestine during embryonic development between hatching $72 \mathrm{hpf}$ and onset of oral feeding (120 hpf). 

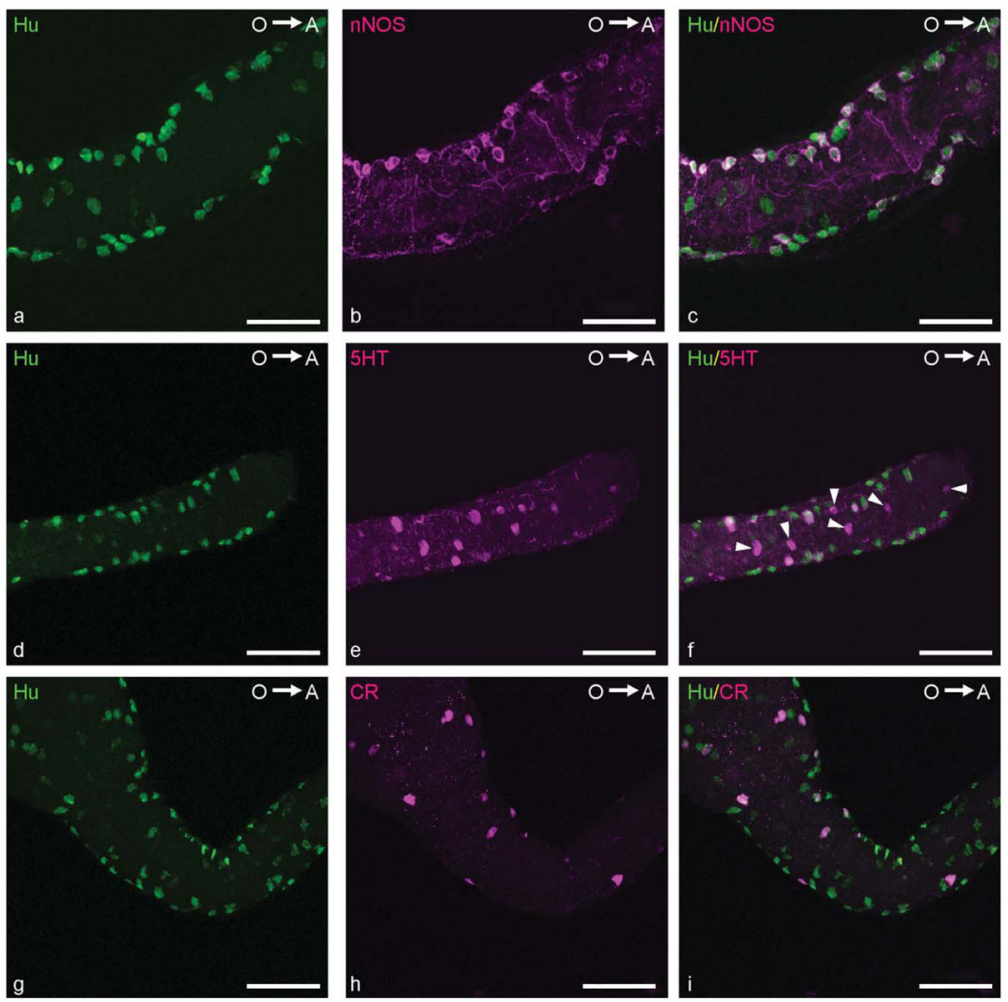

Figure 4.

Confocal images of embryonic zebrafish intestines. a-c: Double immunolabeling with antibodies directed against $\mathrm{Hu}$ (a; green) and nNOS (b; magenta) revealing nitrergic neurons (c; merged) in the MI at 96 hpf. d-f: Double immunostaining with antibodies directed against $\mathrm{Hu}(\mathrm{d}$; green) and 5HT (e; magenta) revealing serotonergic neurons (f; merged) in the DI at 96 hpf. Arrowheads, 5HT-immunoreactive enteroendocrine cells. g-i: CR IR (h; magenta) was observed in enteric neuronal cell bodies (i; merged) immunostained for $\mathrm{Hu}$ (g; green) in the MI at $96 \mathrm{hpf}$. $\mathrm{O} \rightarrow \mathrm{A}$ : From oral to aboral side of the intestine. Scale bars $=50$ $\mu \mathrm{m}$. 

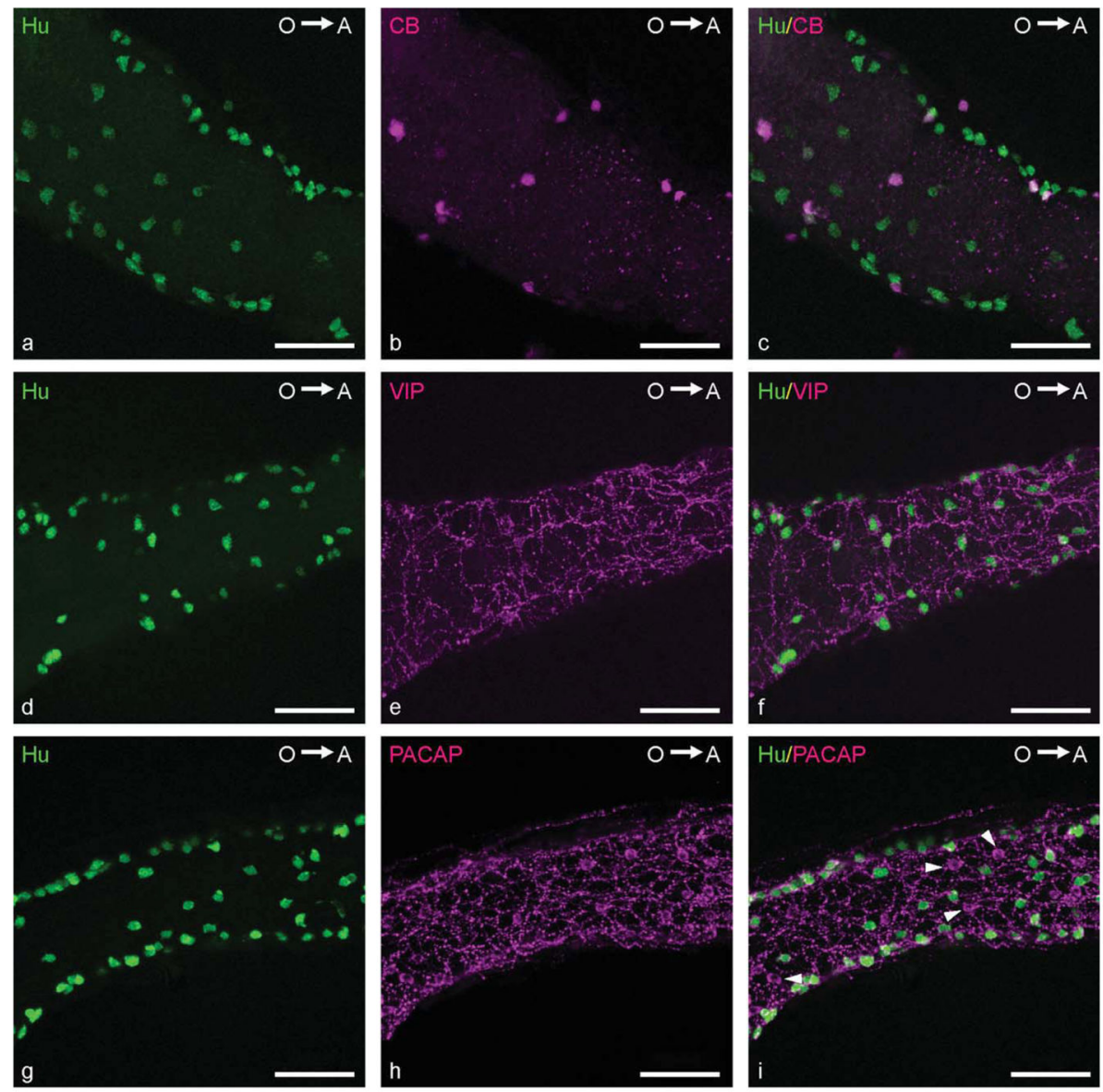

Figure 5.

Confocal images of embryonic zebrafish intestines. a-c: Double immunolabeling with antibodies directed against $\mathrm{Hu}(\mathrm{a}$; green) and CB (b; magenta) showing CB-expressing neurons (c; merged) in the PI at 96 hpf. d-f: Double immunolabeling with antibodies directed against $\mathrm{Hu}$ (d; green) and VIP (e; magenta) showing VIP IR (f; merged) in nerve fibers in the MI at $96 \mathrm{hpf}$. g-i: Double immunostaining for Hu (g; green) and PACAP (h; magenta) showing PACAP-immunoreactive nerve fibers (i; merged) in the MI at $120 \mathrm{hpf}$. Arrowheads, PACAP-expressing epithelial cells. $\mathrm{O} \rightarrow$ A: From oral to aboral side of the intestine. Scale bars $=50 \mu \mathrm{m}$. 

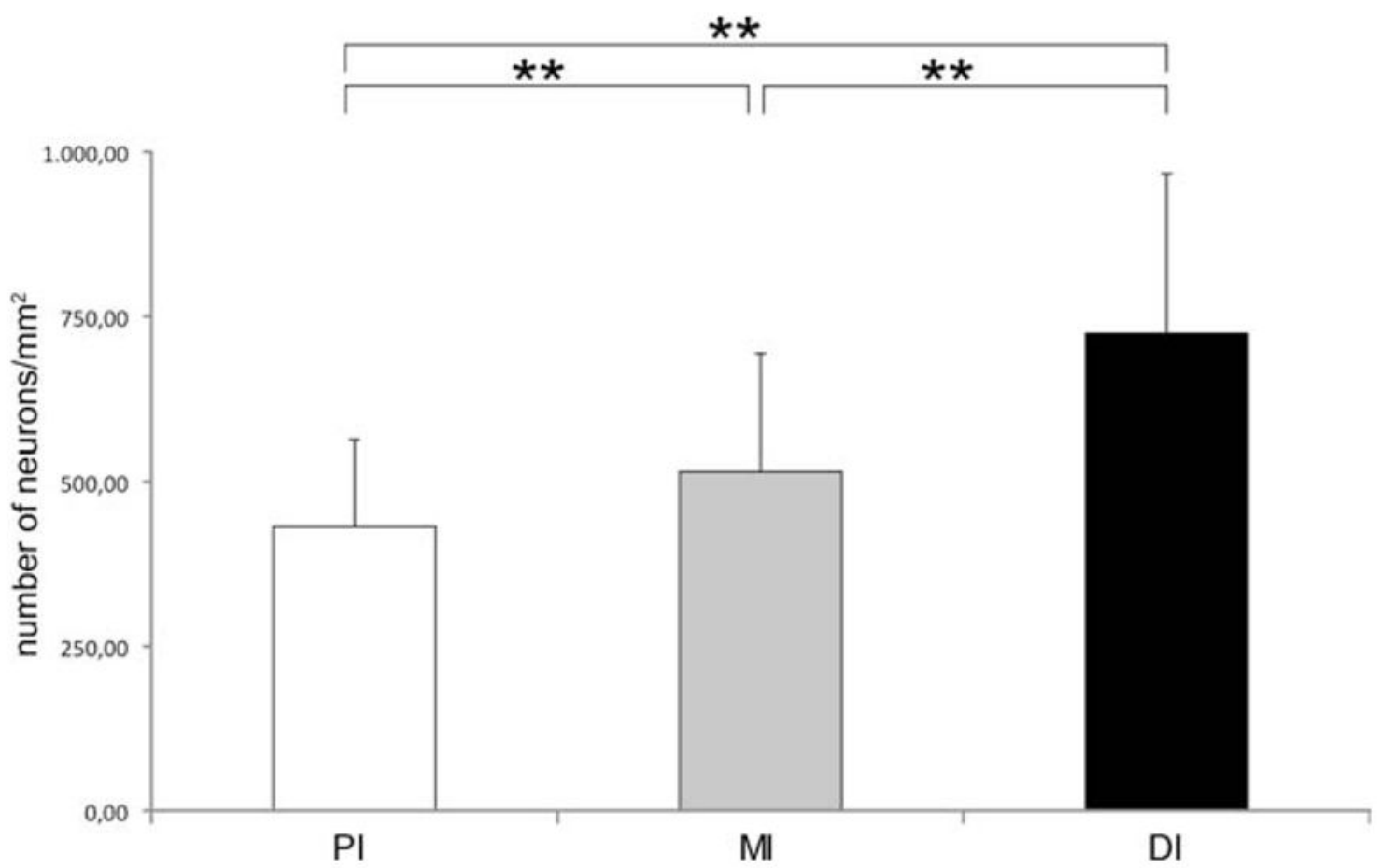

Figure 6.

Number of neurons in different regions of the adult zebrafish intestine calculated per square millimeter. A graph showing that the number of Hu-immunoreactive neurons increased significantly $(* * P<0.0001)$ toward the distal part of the adult intestine. 

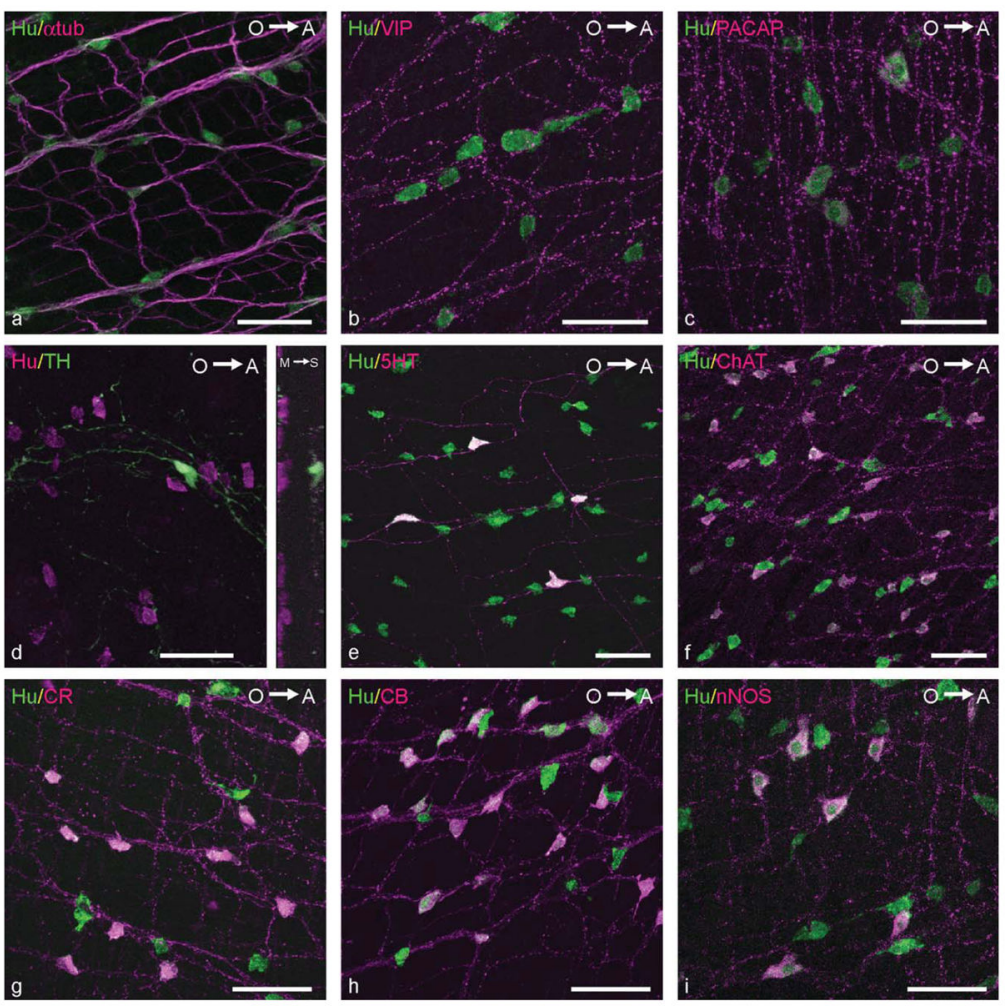

Figure 7.

Merged confocal images of adult zebrafish intestines. a: Double immunolabeling for a-tub (magenta) and Hu (green) revealing the ENS. b,c: Double labeling for VIP or PACAP (magenta) and $\mathrm{Hu}$ (green) showing VIP- or PACAP-immunoreactive varicose nerve fibers in the PI of the adult intestine. d: Double immunostaining for TH (green) and $\mathrm{Hu}$ (magenta) in the PI of the adult intestine, revealing TH-expressing neurons, which are located at the serosal side of the intestine. Inset: Projection of the confocal image in the XY plane and XZ plane, revealing the presence of Hu-IR neurons at both the myenteric and the serosal plane, whereas a TH-IR neuron is confined to the serosal plane. $\mathrm{M} \rightarrow \mathrm{S}$ : From mucosal to serosal side of the intestinal wall. e: Double immunostaining for 5HT (magenta) and Hu (green). f: Double immunolabeling for ChAT (magenta) and $\mathrm{Hu}$ (green). g: Double immunostaining for CR (magenta) and Hu (green). h: Double immunostaining for CB (magenta) and Hu (green). i: Double immunolabeling for nNOS (magenta) and Hu (green) in whole mounts of the adult zebrafish intestine. $\mathrm{O} \rightarrow$ A: From oral to aboral side of the intestine. Scale bars $=50 \mu \mathrm{m}$. 


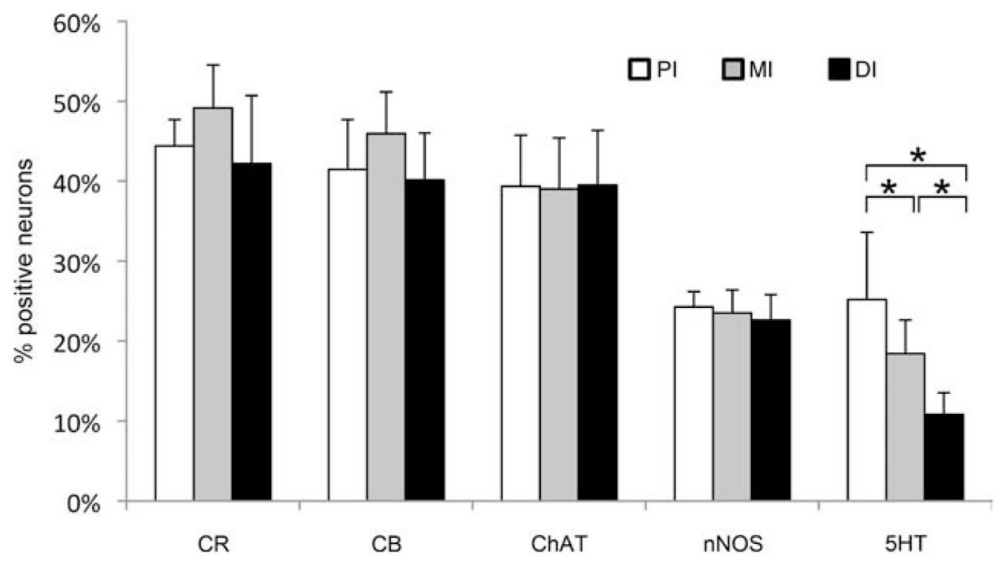

Figure 8.

Average proportional distribution of enteric neurons expressing $\mathrm{CR}, \mathrm{CB}, \mathrm{ChAT}$, nNOS, or 5HT in the proximal (PI), middle (MI), and distal (DI) parts of the adult intestine.

Proportional distribution for most markers remained constant over the three intestinal parts, except for 5HT, which significantly decreased $(* P<0.05)$ along the length of the intestine. 

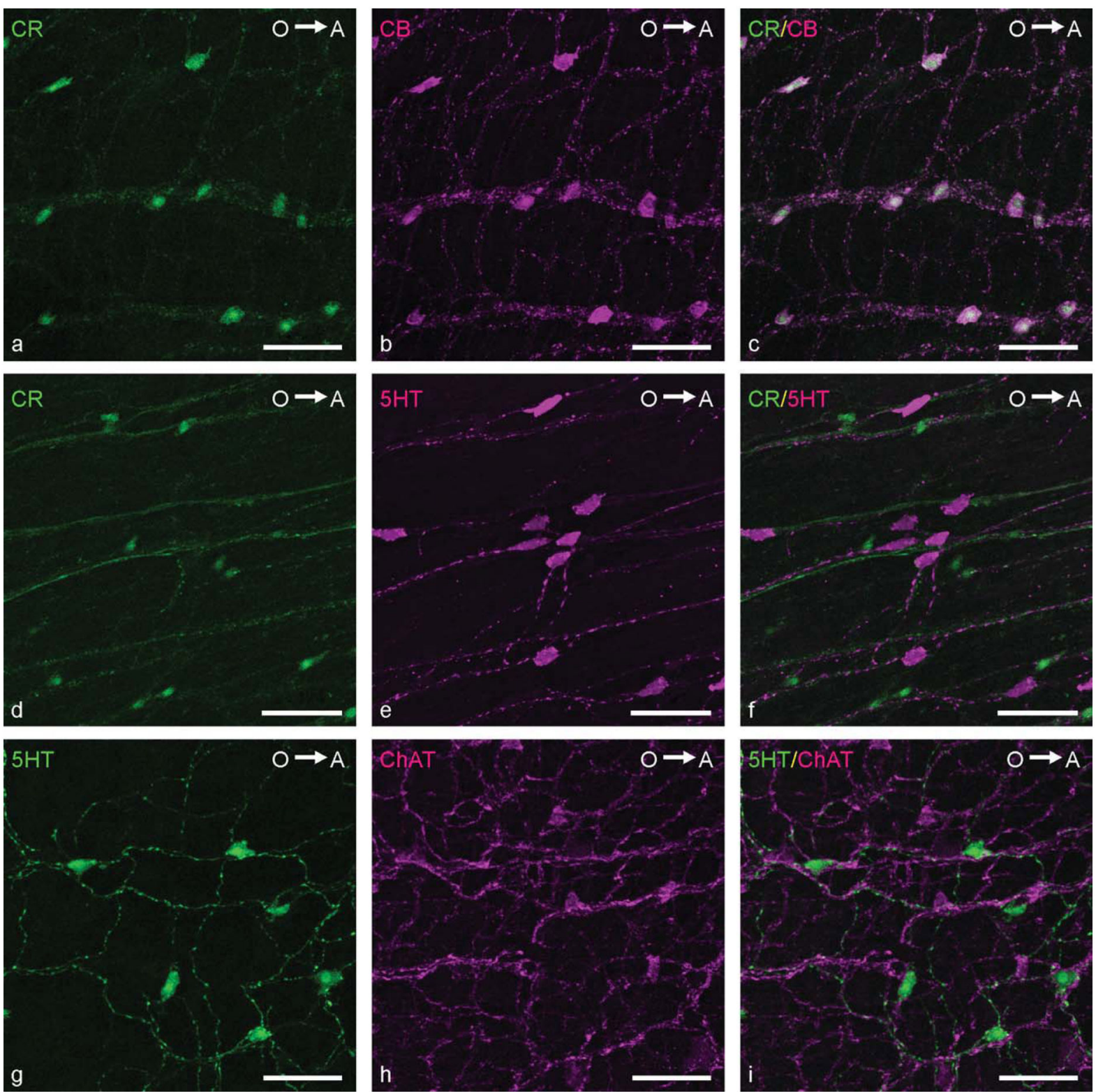

Figure 9.

Confocal images showing the coexpression of neurochemical markers in the ENS of the adult zebrafish. a-c: CR (a; green) and CB (b; magenta) were expressed in the same neurons (c; merged). d-f: No colocalization of CR (d; green) and 5HT (e; magenta) was detected (f; merged). g-i: No coexpression of 5HT (g; green) and ChAT (h; magenta) was observed (i; merged). $\mathrm{O} \rightarrow \mathrm{A}$ : From oral to aboral side of the intestine. Scale bars $=50 \mu \mathrm{m}$. 

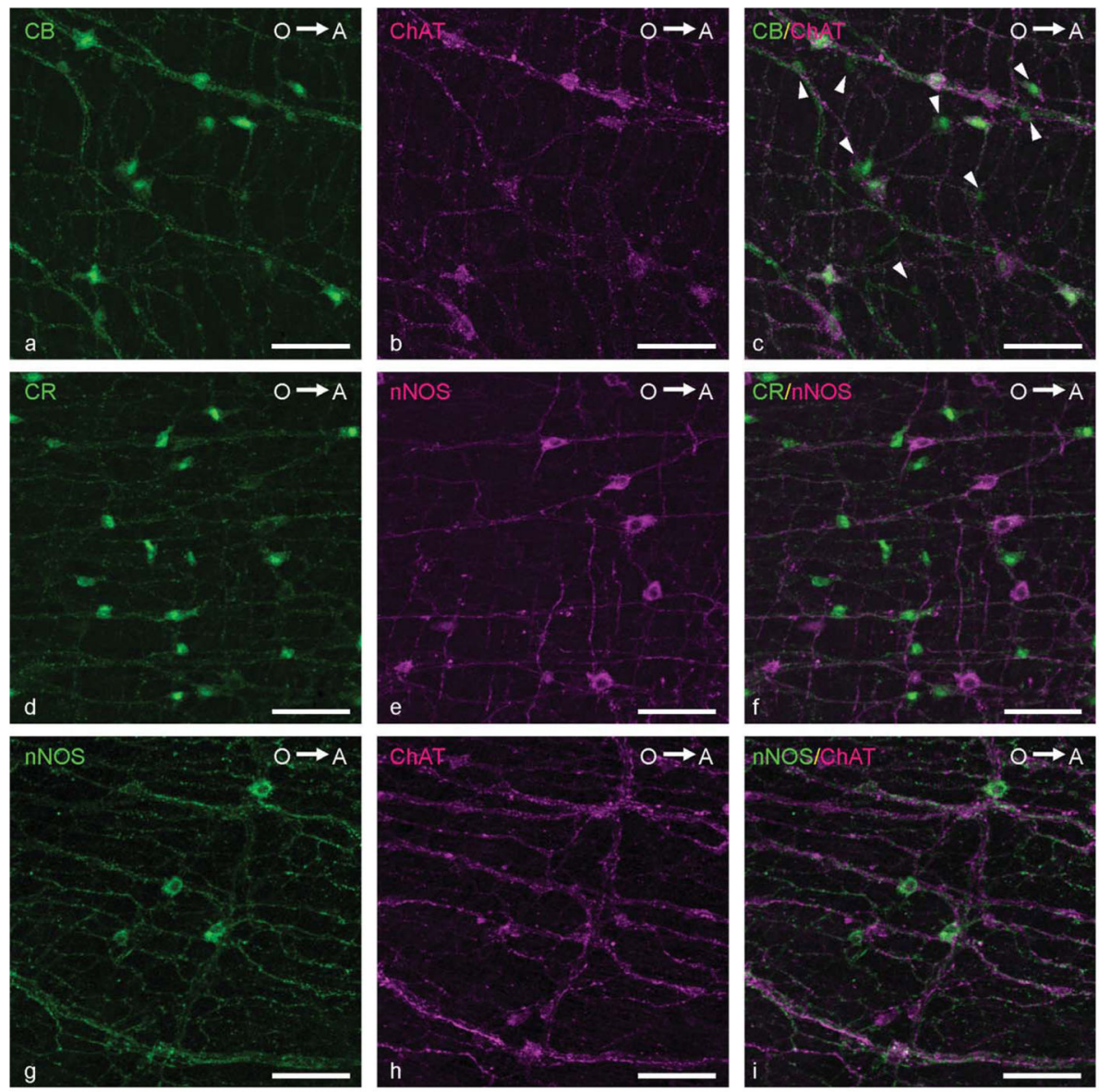

Figure 10.

Confocal images showing the coexpression of neurochemical markers in the ENS of the adult zebrafish. a-c: Colocalization of CB (a; green) and ChAT (b, magenta; c, merged). Arrowheads, neurons expressing only CB. d-f: Colocalization of CR (d; green) and nNOS (e, magenta; f, merged). g-i: Colocalization of nNOS (g; green) and ChAT (h, magenta; i, merged). $\mathrm{O} \rightarrow \mathrm{A}$ : From oral to aboral side of the intestine. Scale bars $=50 \mu \mathrm{m}$. 

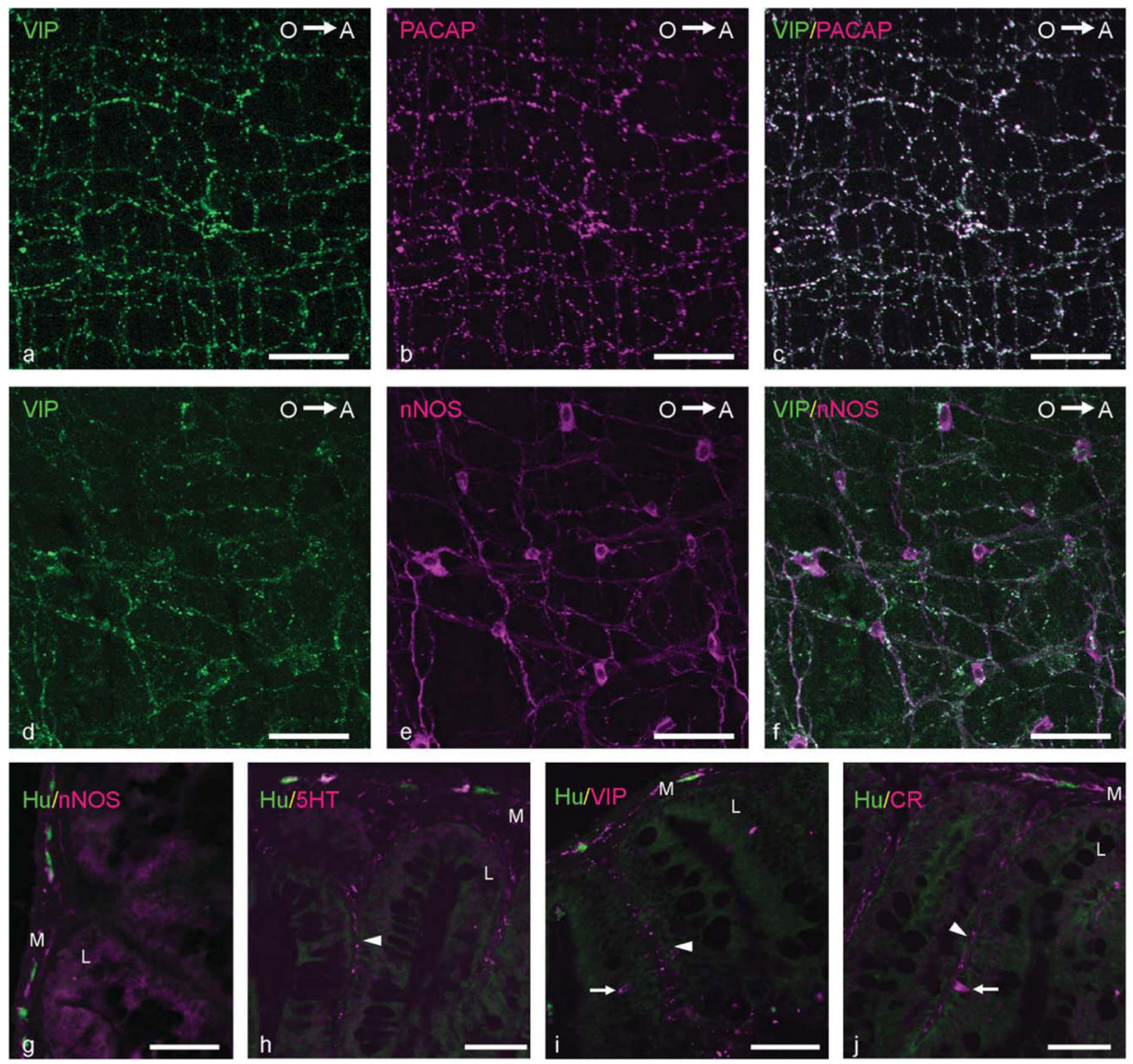

Figure 11.

a-f: Confocal images showing the coexpression of VIP (a; green) and PACAP (b; magenta) and of VIP (d; green) and nNOS (e; magenta) in enteric nerve fibers (c,f: merged). $\mathrm{O} \rightarrow \mathrm{A}$ : From oral to aboral side of the intestine. $\mathbf{g}-\mathbf{j}$ : Merged images of cryosections the MI of the adult zebrafish. g: Double immunolabeling with antibodies directed against nNOS (magenta) and $\mathrm{Hu}$ (green) revealing nitrergic nerve fibers in the tunica muscularis (M). h: Double immunostaining with antibodies directed against 5HT (magenta) and Hu (green) revealing serotonergic nerve fibers in the tunica muscularis and the lamina propria (L). i: Double immunolabeling with antibodies directed against VIP (magenta) and Hu (green) showing VIP-expressing nerve fibers in the tunica muscularis and the lamina propria. $\mathrm{j}$ : Double immunostaining for $\mathrm{Hu}$ (green) and $\mathrm{CR}$ (magenta) showing CR-positive nerve fibers in the tunica muscularis and the lamina propria. Arrowheads, immunoreactive nerve fibers in the lamina propria; arrows, immunoreactive epithelial cells. Scale bars $=50 \mu \mathrm{m}$. 


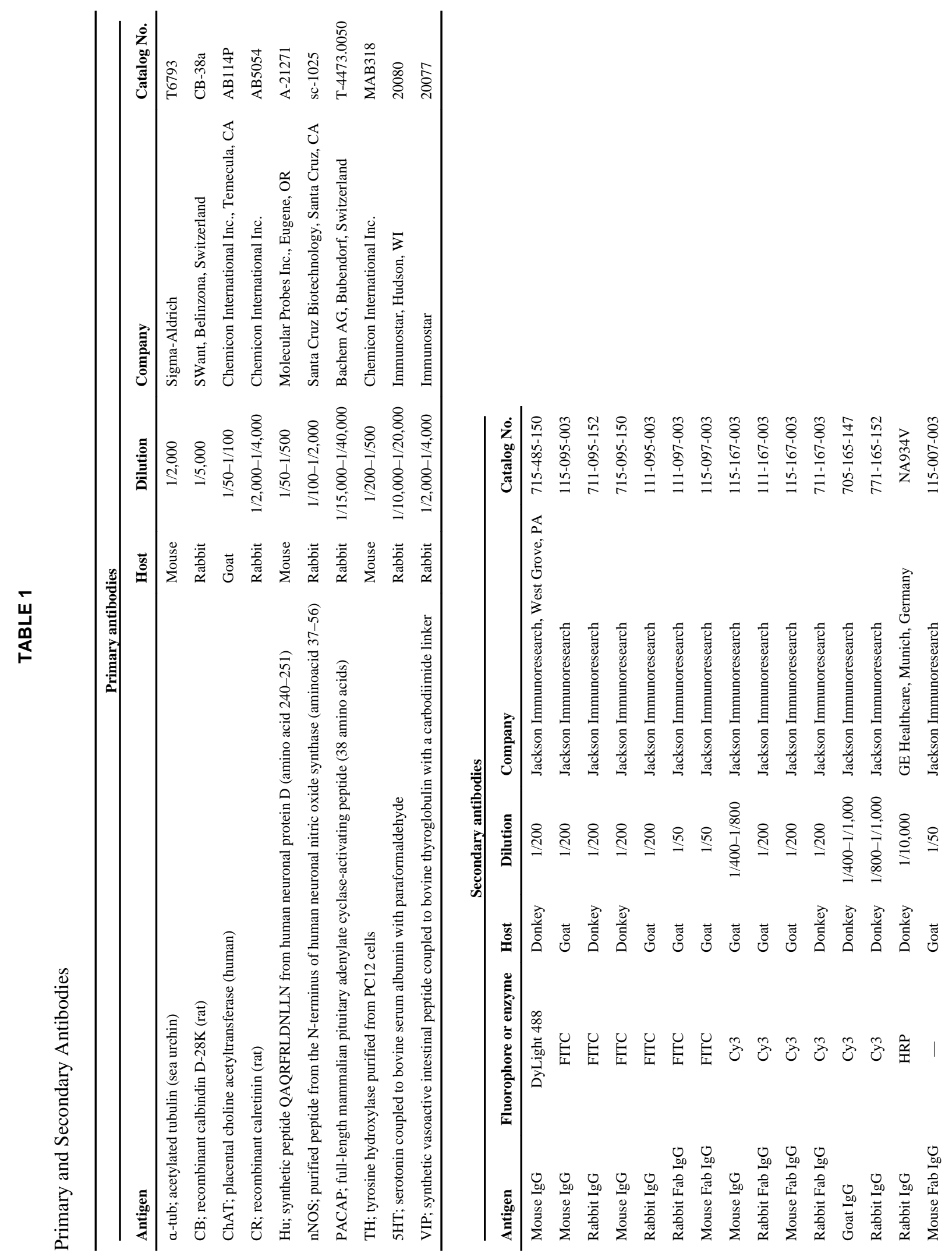




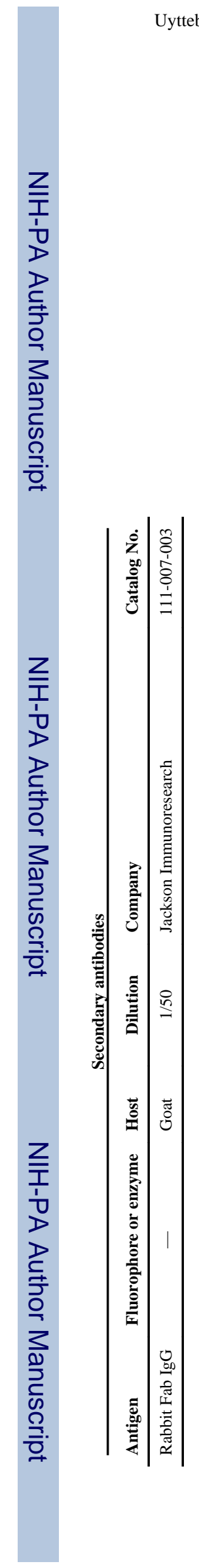




\section{TABLE 2}

Proportional Expression of Neurochemical Markers in Hu-Labeled Myenteric Neurons of the Adult Zebrafish

\begin{tabular}{lcccc}
\hline & PI (\%) & MI (\%) & DI (\%) & Mean (\%) \\
\hline 5HT & $25 \pm 8$ & $18 \pm 4$ & $11 \pm 3$ & 18 \\
nNOS & $24 \pm 2$ & $24 \pm 3$ & $23 \pm 3$ & 23 \\
ChAT & $39 \pm 6$ & $39 \pm 6$ & $40 \pm 7$ & 39 \\
CB & $41 \pm 7$ & $46 \pm 5$ & $40 \pm 6$ & 43 \\
CR & $44 \pm 4$ & $49 \pm 5$ & $42 \pm 9$ & 45 \\
\hline
\end{tabular}


